\title{
„Schon so lange wird Germanien besiegt!“ Rom, ein gescheiterter Sieger?*
}

\author{
Rainer Wiegels
}

\section{1. „... und noch in jüngster Zeit hat man mehr triumphiert als Siege errungen“}

„Tam diu Germania vincitur“ - „Schon so lange wird Germania besiegt“, und auch heute triumphiert man wieder über sie, urteilt Tacitus in seiner 98 n.Chr. verfassten bzw. redigierten Schrift, der „Germania“. ${ }^{1}$ (Abb. 1) Die berühmte Feststellung findet sich innerhalb eines Exkurses in der Mitte des sorgfältig durchkomponierten Werkes, wodurch sie besonderes Gewicht erhält und zweifellos auch erhalten sollte. ${ }^{2}$ An dieser Stelle verlässt Tacitus bewusst die ethnographische Form der Schrift und fällt als Historiker auf ungewöhnlich direkte Art und Weise sein resigniertes oder auch sar-

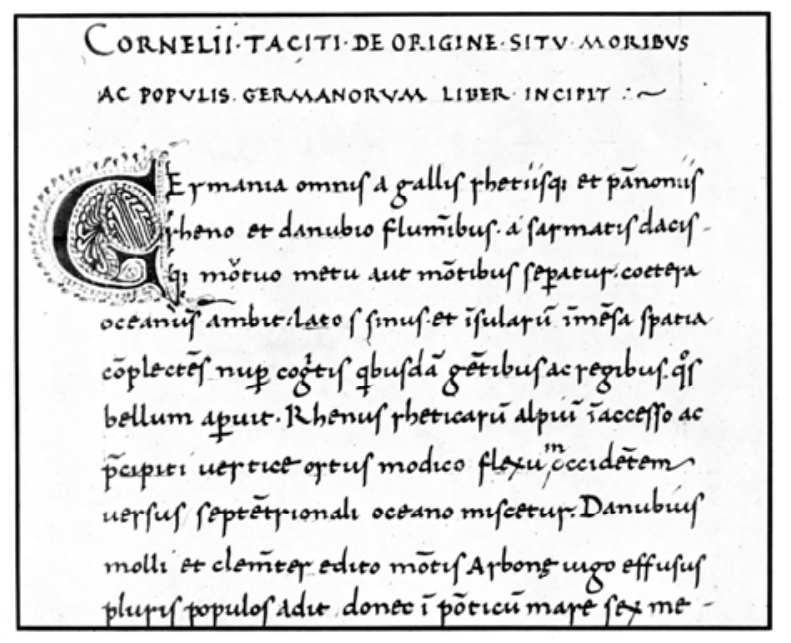

Abb. 1: Der Anfang von Tacitus ,Germania‘ im Codex Leidensis (1460) kastisches Urteil über zweihundertzehn Jahre römisch-germanischer Geschichte von den Kimbernkriegen Roms 113 v.Chr. an bis hin zur aktuellen Gegenwart, dem 2. Konsulat des Kaisers Trajan 98 n.Chr. Mit knappen und zugespitzten Formulierungen wird ein großer historischer Bogen geschlagen mit Hervorhebung der seiner Meinung nach wichtigsten Stationen jenes zu einem grundsätzlichen Konflikt stilisierten Verhältnisses, in welchem sich Siege mit Niederlagen abgewechselt hätten und in dem sich die Freiheit der Germanen als kraftvoller und wirkungsvoller erwiesen habe als das Königtum der östlichen Widersacher Roms, nämlich der Parther. (Abb. 2) Den Höhepunkt an verheerenden Niederlagen markiert aber diejenige des Varus 9 n.Chr., die den Untergang von drei Legionen und den Tod des Feldherrn zur Folge hatte. Sie verdient noch grö-

\footnotetext{
* Für die Veröffentlichung mit einigen Anmerkungen versehener und leicht überarbeiteter Vortrag aus Anlass der Verleihung des Ausonius-Preises der Universität Trier an den Autor im Jahre 2009.

${ }^{1}$ Tac. Germ. 37, 2.

${ }^{2}$ Die Literatur zur „Germania“ des Tacitus im Allgemeinen und zum zentralen Kapitel 37 im Besonderen ist beinahe uferlos. Es kann an dieser Stelle nur auf einige weiterführende Werke, insbesondere Kommentare, verwiesen werden: P. Cornelius Tacitus, Germania, interpretiert, herausgegeben, übertragen, kommentiert u. mit einer Bibliographie versehen von A. A. LUND (Heidelberg 1988); Tacitus, Germania, lat. u. deutsch von G. PERL (Berlin 1990) (= Griech. u. lat. Quellen zur Frühgesch. Mitteleuropas bis zur Mitte des 1. Jahrtausends u. Z., Zweiter Teil); Beiträge zum Verständnis der Germania des Tacitus, Teil I, hrsg. von H. JANKUhN und D. TIMPE (Göttingen 1989); Teil II, hrsg. von G. NEUMANN u. H. SEEMANN (Göttingen 1992); A. A. Lund, Zur Gesamtinterpretation der Germania des Tacitus, in: Aufstieg und Niedergang der Römischen Welt (ANRW) II 33.3 (Berlin/New York 1991) 1858-2382; D. TIMPE, Romano-Germanica: Gesammelte Studien zur Germania des Tacitus (Stuttgart/ Leipzig 1995); J.-W. BECK, ,Germania“ - ,Agricola‘: Zwei Kapitel zu Tacitus’ zwei kleinen Schriften. Untersuchungen zu ihrer Intention und Datierung sowie zur Entwicklung ihres Verfassers. (Hildesheim 1998) (= Spudasmata 68); J. B. RIVES, Tacitus: Germania (Oxford 1999); ST. SCHMAL, Tacitus (Hildesheim 2005); D. TIMPE, Die Germania des Tacitus. Ethnographie und römische Zeitgeschichte, in: H. SCHNEIDER (Hrsg.), Feindliche Nachbarn. Rom und die Germanen (Köln/Weimar/Wien 2008) 167200. - Allgemein immer noch grundlegend zu Tacitus R. SYME, Tacitus (Oxford 1958).
} 


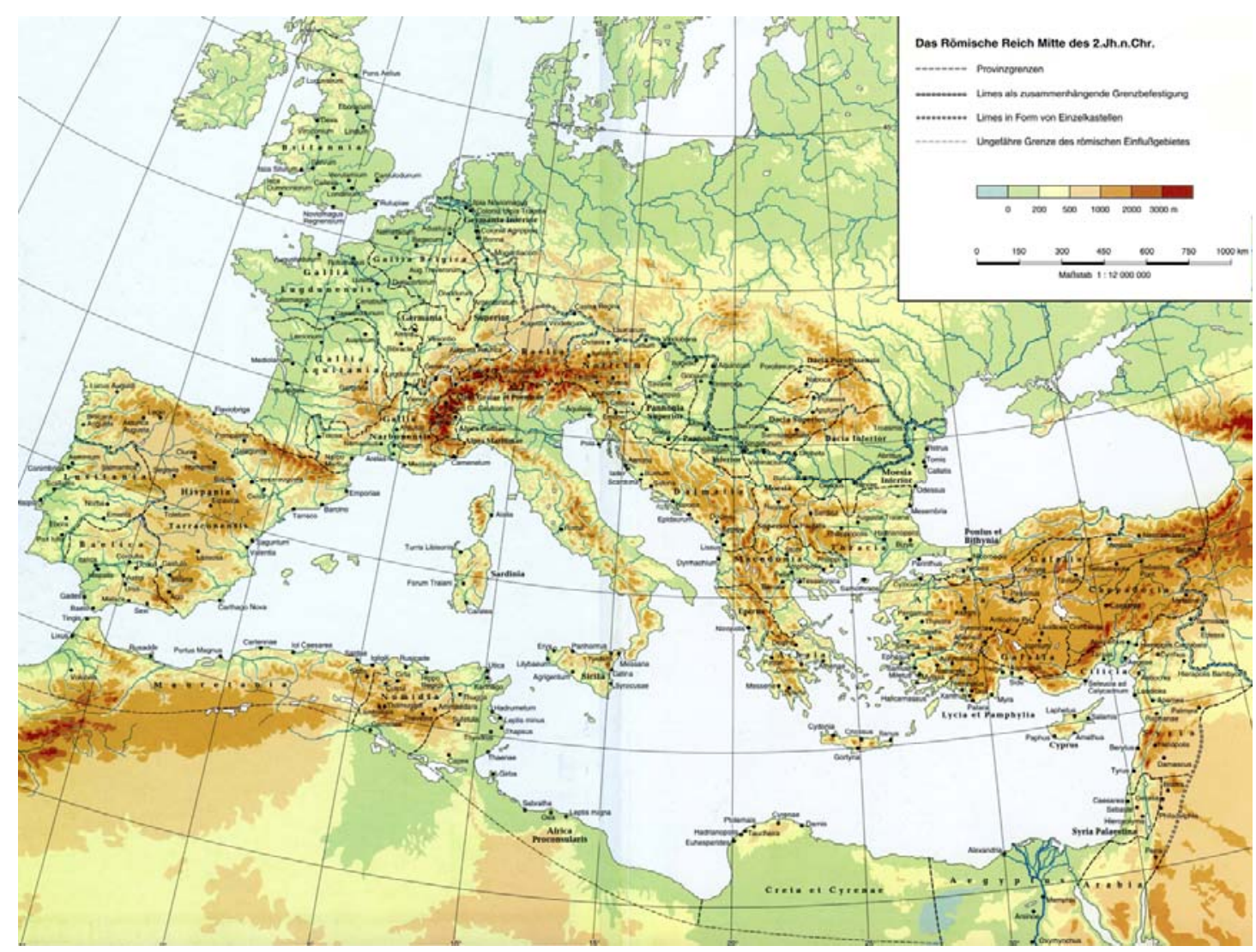

Abb. 2: Imperium Romanum

ßere Beachtung, weil sie sogar - wie Tacitus ausdrücklich hervorhebt - unter dem Princeps Augustus, also dem neuen Herrschaftssystem, erlitten wurde. Verlustreich seien überdies selbst die römischen Siege des Marius in Italien kurz vor 100 v.Chr., des Caesar in Gallien in den 50er Jahren des 1. vorchristlichen Jahrhunderts und des Drusus, Tiberius und Germanicus in Germanien gewesen, also die Kämpfe im Gebiet der Germania magna östlich des Rheins zwischen 12 v. und 16 n.Chr. Zum Gespött seien die gewaltigen Drohungen des Kaisers Caligula anlässlich seines Germanienfeldzuges 39/40 n.Chr. geworden. Danach habe zunächst Ruhe geherrscht, bis in den Bürgerkriegen des Vierkaiserjahres Germanen sogar die Winterlager am Rhein erobert und ganz Gallien für sich zu gewinnen versucht hätten, bevor sie wieder vertrieben wurden. Bei nächster sich bietender Gelegenheit seien dann mehr Triumphe gefeiert als wirkliche Siege errungen worden. ${ }^{3}$ Diese letzte bissige Bemerkung mit einer zugespitzten Antithese zielt auf die Feldzüge und Siegesfeiern des kurz zuvor im Jahr 96 n.Chr. gestürzten und ermordeten Kaisers Domitian. Dieser war auf Beschluss des Senates der damnatio memoriae, also dem Auslöschen jedes Andenkens an ihn, verfallen. Tacitus nennt den unberechtigten Triumphator denn auch verächtlich nicht beim Namen, über den ohnehin niemand im Zweifel sein konnte.

Das Urteil über die sich über Jahrhunderte hinziehenden kriegerischen Auseinandersetzungen zwischen Römern und Germanen ist bemerkenswert, stammt es doch von einem Mitglied der obersten römischen Aristokratie, die ihr Selbstverständnis traditionell aus der Partizipation an der Politik bezog. Dem ersten Anschein nach wird zwar von Tacitus ein historischer Rückblick gegeben, und das soll er auch sein. ${ }^{4}$ Aber

\footnotetext{
${ }^{3}$ Germ. 37, 2-5.

${ }^{4}$ Zur Ereignisgeschichte selber sei hier nur auf den Überblick von D. TIMPE/B. SCARDIGLI, Germanen, Germania, Germanische Altertumskunde I: Geschichte, in: RGA² (Studienausgabe) (Berlin/New York
} 
dieses nicht allein. Die Aufzählung beginnt mit den Niederlagen Roms, dann folgen verlustreiche, aber tatsächlich erfochtene Siege und schließlich die nur scheinbar errungenen Siege, wobei im Verlauf des Bataveraufstandes lediglich der Status quo an der Rheinfront wiederhergestellt werden konnte. In der Bilanz - so Tacitus - seien jedenfalls über die Zeiten hinweg bis an die Wende zum 2. Jahrhundert n.Chr. Siege über die Germanen mehr mit großem propagandistischen Aufwand gefeiert als wirklich erzielt worden. Eben: Tam diu Germania vincitur. Der Höhepunkt dieser Farce liegt für ihn in der jüngsten Vergangenheit. Mit ihr galt es in erster Linie abzurechnen. ${ }^{5}$ Gemessen an den einst gesteckten großen Zielen und vordergründig propagierten triumphalen Erfolgen kann daher für Tacitus im nachbetrachtenden Urteil lediglich das bisherige Scheitern Roms in Germanien konstatiert werden.

Über die mit diesem Exkurs in seinem Frühwerk verbundenen Absichten des Historikers ist in der Vergangenheit ebenso gerätselt worden wie über die Intentionen, welche Tacitus überhaupt mit seiner „Germania“ verband. Die zahlreichen Deutungsversuche legen den Schluss nahe, dass mehrere Motive die Wahl des Gegenstandes bestimmt haben. ${ }^{6}$ Dass Tacitus jedenfalls mit dieser Schrift ebenso wie mit seinem nahezu zeitgleichen „Agricola“, der biographisch angelegten Schrift über das Wirken seines Schwiegervaters vor allem in Britannien, und dem „Dialogus“ über die Redekunst Geschichte und Politik seiner eigenen Zeit deuten und gestalten wollte, kann nicht bezweifelt werden. ${ }^{7}$ Seiner eigenen Aussage entsprechend plante er zunächst, im Anschluss an die kleineren Schriften die Regierungszeit Domitians (81-96 n.Chr.) mit ihrer Unterdrückung der senatorischen Freiheit und das danach angebrochene hoffnungsvolle gute Zeitalter Nervas (96-98 n.Chr.) und Trajans (ab 98 n.Chr.) umfassend zu behandeln. Im Prooemium zum „Agricola“ hatte er notiert, dass, wie die alte Zeit gemeint ist diejenige der Republik - das äußerste Maß an Freiheit aufwies, so die 15 Jahre domitianischer Schreckensherrschaft das äußerste Maß an Knechtschaft. Doch

1998) 1-79 sowie auf R. WOLTERS, Römische Eroberung und Herrschaftsorganisation in Gallien und Germanien. Zur Entstehung und Bedeutung der sogenannten Klientel-Randstaaten (Bochum 1990) (= Bochumer hist. Studien, Alte Geschichte Nr. 8) verwiesen. In unserem Zusammenhang spielen die jeweiligen politischen und militärischen Vorgänge als solche nur eine untergeordnete Rolle, so dass auf eingehende Einzelanalysen verzichtet werden kann.

${ }^{5}$ Grundlegend H. Nesselhauf, Tacitus und Domitian. Hermes 80, 1952, 222-245. Vgl. ferner K. STROBEL, Der Chattenkrieg Domitians. Germania 65, 1987, 423-452; A. BECKER, Rom und die Chatten (Darmstadt/Marburg 1992) bes. 265-305.

${ }^{6}$ Vgl. dazu die Literatur in Anm. 2 mit den weiteren Verweisen. Dazu R. WIEGELS, Zur deutenden Absicht von Tacitus' Germania, in: Aspekte römisch-germanischer Beziehungen in der Frühen Kaiserzeit, hrsg. von G. FRANZIUS (Espelkamp 1995) (= Schriftenreihe Kulturregion Osnabrück des Landschaftsverbandes Osnabrück e. V. 6) 155-176.

${ }^{7}$ Vgl. zum „Agricola“ etwa R. M. OgILVIE/I. Richmond, Cornelii Taciti, De vita Agricolae (Oxford 1967). - Für die Geschichte des römischen Britannien im ersten Jahrhundert ist diese Schrift von erstrangiger Bedeutung. Inhalt und Wertungen sind daher Gegenstand zahlreicher Untersuchungen insbesondere aus dem angelsächsischen Bereich. In unserem Zusammenhang geht es allein um die historische Gesamtsicht des Autors, wie sie in den verschiedenen Schriften zum Ausdruck kommt. - Auf den „Dialogus“ braucht hier nicht näher eingegangen zu werden. An dieser Stelle nur so viel: Tacitus, dem wir diese Schrift trotz geäußerter Bedenken zuschreiben, knüpft mit der von ihm gewählten Form des Dialogs an Cicero an, mit dem bekanntlich die Reihe der lateinischen Dialoge beginnt. Diese literarische Form, welche bei den Griechen wie etwa bei Plato und Aristoteles vielfach genutzt wurde, war dazu geeignet, ein Problem aus unterschiedlicher Perspektive zu analysieren (vgl. Tac. dial. 1,3). Im „Dialogus“ werden einmal mehr die alten Zeiten gegen die neuen ausgespielt - und umgekehrt - mit dem Ergebnis, dass letztlich nach Tacitus die Redekunst unter den alten Bedingungen besser gedeihen konnte als gegenwärtig. Dabei verwischen sich die Zeitverhältnisse noch zusätzlich dadurch, dass das Gespräch selber, an dem Tacitus in seiner Jugend teilgenommen haben will, in die Regierungszeit Vespasians verlegt wird. Welche Folgerungen sich hieraus für das Geschichtsbewusstsein des Historikers ziehen lassen, wird man nur im Rahmen einer Gesamtinterpretation ermessen können. 
jetzt sei der Mut zurückgekehrt. Nerva habe zu Beginn des glückseligsten Jahrhunderts einst unvereinbar erscheinende Dinge, nämlich Principat und Freiheit, miteinander versöhnt, Trajan aber habe das Glück noch vermehrt. So wolle er ein Denkmal früherer Knechtschaft und ein Zeugnis gegenwärtigen Glücks erstellen. ${ }^{8}$ Den Plan hat Tacitus in dieser Form offenbar mit Bedacht und gemäß aktuell gewonnenen, neuen Erfahrungen nicht realisiert. Die um 109 n.Chr. abgeschlossenen „Historien“ setzen einerseits mit dem Tod des Kaisers Nero 68 n.Chr. ein, umfassen also die gesamte flavische Epoche, andererseits bleibt das neue Zeitalter unbehandelt. In den im zweiten Jahrzehnt des 2. Jahrhunderts n.Chr. verfassten „Annalen“ erfolgt dann der Rückgriff auf die iulisch-claudische Epoche ab dem Tod des ersten Princeps Augustus 14 n.Chr. Ein „Zeugnis gegenwärtigen Glücks“ wird auch weiterhin nicht geliefert. Dieses gilt es bei der Beurteilung auch der nur einen Ausschnitt der gesamten römischen Geschichte betreffenden Äußerungen des Historikers zur römischen Germanenpolitik mit zu bedenken. Für Tacitus waren es zunächst die Erfahrungen der domitianischen Ära und die Art und Weise, wie er und seine Standesgenossen diese Phase erlebt haben oder auch erleben mussten, die sich schon in den Frühschriften niedergeschlagen haben. ${ }^{9}$ Später kommen die neuen Erfahrungen der trajanischen Epoche hinzu.

Dass Tacitus mit seinem „Agricola“ eine biographische Schrift verfasste, mag man vordergründig damit erklären, dass er mit Cn. Iulius Agricola seinen Schwiegervater in Erfüllung einer Pietätspflicht wie mittels einer traditionellen laudatio funebris ehren wollte. Gleich die ersten Worte der Schrift aber zeigen, dass sein Anliegen weit darüber hinaus geht. Agricola wird in die Reihe herausragender Männer eingeordnet, deren Taten und Verhaltensweisen (facta moresque) den Nachfahren zur beispielhaften Nachahmung überliefert und dem Vergessen oder dem neidischen Verschweigen entrissen werden müssen. ${ }^{10}$

Schwieriger zu entschlüsseln sind die tieferen Gründe für den Plan des Historikers aus nahezu derselben Zeit, eine „Germania“ mit dem vernichtenden Urteil über die mehr gefeierten als wirklich errungenen Siege zu verfassen. Ethnographische Abhandlungen über Völkerschaften waren an sich in Rom nicht unbekannt. Sie wurden von siegreichen Feldherren in ihre Memoiren nach dem Muster von Caesars „Bellum Gallicum“ als Exkurse eingearbeitet, und dementsprechend enthält auch der „Agricola“ einen solchen über Land und Leute Britanniens. Ein Prooemium, in welchem gewöhnlich auch über Anlass und Zielsetzungen eines Werkes Auskunft gegeben wird, ist der „Germania“ des Tacitus nicht vorangestellt, so dass die Absicht - oder auch die Absichten -, welche Tacitus mit seiner Monographie verband, nur aus der immanenten Textinterpretation unter Berücksichtigung der aktuellen Zeitverhältnisse erschlossen werden können bzw. erschlossen werden müssen. Es liegt nahe, zumindest ein Motiv für die Abfassung der Schrift in eben dieser Diskrepanz zwischen Anspruch und Wirklichkeit zu sehen, welche in den Siegesfeiern und im Triumph Domitians über Germanien nach Meinung des Historikers gleichsam ihren perversen Höhe-

\footnotetext{
${ }^{8}$ Tac. Agr. 2 f.

${ }^{9}$ In den „Historien“ wird dieser Abschnitt der römischen Geschichte dann eingebettet in einen größeren historischen Kontext, wobei es nicht abwegig ist zu vermuten, dass Tacitus als erster oder zumindest als einer der ersten eine historische Analyse vor allem der Zeit Domitians vorgenommen und über sie ein generelles Urteil gefällt hat, welches auch für die Folgezeit weitgehend verbindlich wurde und so auch dasjenige späterer Historiker nachhaltig geprägt hat. Zweifellos wüssten wir Genaueres, wenn nicht die diesbezüglichen Teile der „Historien“ verloren wären. Sich von seiner nachwirkenden Einschätzung der domitianischen Zeit zu lösen, fällt dementsprechend auch heute noch mangels nicht gerade zahlreicher, von einem negativen Geschichtsbild freier und daher gleichsam ,unverdächtiger“ späterer Quellen schwer.

${ }^{10}$ Vgl. auch das gesamte Prooemium Tac. Agr. 1-3.
} 
punkt erreichte. Es galt, den Dunstschleier zu zerreißen, der mit Bedacht vor eine Wirklichkeit gezogen worden war, die ganz anders aussah als vorgespiegelt. Ein entsprechendes Anliegen lässt sich unschwer auch dem „Agricola“ entnehmen. Auch hier ist es nicht zuletzt die Diskrepanz von Schein und Wirklichkeit, die es in den politischen Vorgängen aufzudecken gilt. Sie durchzieht als ein roter Faden nicht nur die Frühschriften des Historikers und bestimmt sein Erkenntnisinteresse. Entsprechend verlaufen die Trennlinien der moralischen Bewertungen: Leistung und versagte Anerkennung auf der einen - Versagen und propagierte Leistung auf der anderen Seite. Dieses charakterisiert das Verhältnis zwischen neidischen Principes wie Tiberius, Caligula und nicht zuletzt Domitian und führenden Persönlichkeiten, soweit sich diese jedenfalls bemühten, altrömischen Idealen und Wertvorstellungen gerecht zu werden. (Abb. 3)

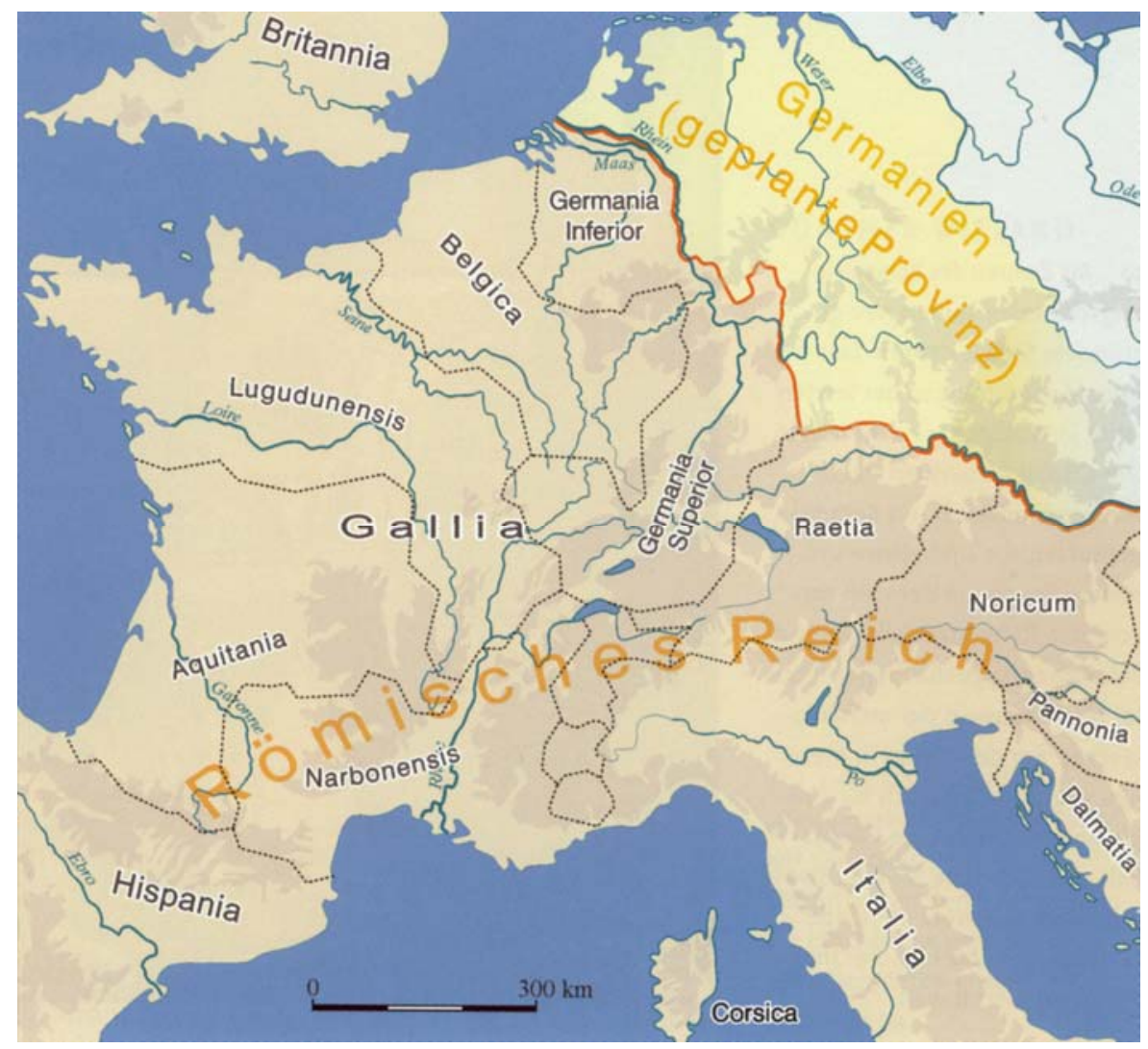

Abb. 3: Die geplante Provinz Germania

Man hat in den kritischen Feststellungen des Historikers die Aufforderung zur Wiederaufnahme eines offensiven Vorgehens gegen Germanien sehen wollen oder zumindest die Hoffnung darauf. Das dürfte mitspielen, vermag aber nicht allein die Wahl von Thema und darstellerischer Form und des Weiteren überhaupt die Hinwendung zur Geschichtsschreibung zu erklären. Im Einleitungssatz zur „Germania“ heißt es in deutlicher Anlehnung an den Beginn von Caesars „Bellum Gallicum“: „Germanien wird in Gänze von den Galliern, Rätern und Pannoniern - d.h. also im Westen und Süden - durch die Flüsse Rhein und Donau, von den Sarmaten und Dakern - also im Osten - durch gegenseitige Furcht oder durch Gebirgszüge geschieden, das übrige - also der Norden - umgibt der Ozean.“ Germanien wird dabei als großräumige Einheit dem Imperium Romanum gegenübergestellt. Schon hier kündigt sich an, dass entgegen der Leistung Caesars, der ganz Gallien (Gallia omnis) unterworfen hat, dieses bei der Germania omnis immer noch nicht gelungen ist. Die Nähe der von Tacitus 
beschriebenen Umgrenzung Germaniens zu derjenigen, die Pomponius Mela in seiner „Chronographia“ (Länderkunde) um die Mitte des 1. Jahrhunderts n.Chr. vorgenommen hat, ist offenkundig und weist auf eine verbreitete Sicht. Auch Mela nennt den Rhein, den Ozean und das Siedlungsgebiet der Sarmaten als Begrenzungen, für den Süden allerdings nicht die Donau, sondern die Alpen. ${ }^{11}$ Ebenso übernimmt der jüngere Seneca um dieselbe Zeit die schon von Caesar nicht ohne politische Absichten getroffene Festlegung des Rheins als Grenze zwischen Gallien und Germanien, doch sei die Donau jedenfalls in ihrem oberen Verlauf von Rom schon in augusteischer Zeit überschritten worden. ${ }^{12}$ Seit Caesar stand für die Römer fest, dass der Rhein zwei ursprünglich zwar verwandte, in ihrer zivilisatorischen Entwicklung aber unterschiedliche Völker trennte, nämlich Gallier und Germanen. Tacitus hält sich an dieses Grundverständnis, was auch mit der Vorliebe in der Antike für klare Wassergrenzen zu tun hat. Er ignoriert an dieser Stelle auch die ihm selbstverständlich bekannte Tatsache, dass nach der in der jüngeren Vergangenheit erfolgten Okkupation größerer Gebiete im obergermanischen Bereich der Rhein von Koblenz an südwärts und die Donau bis etwa Regensburg nicht mehr die eigentlichen Grenzlinien markierten, sondern sich das Reichsgebiet darüber hinaus erstreckte. Letztlich wurden die hinzugewonnenen Gebiete jedoch eher als Vorfeldsicherung Galliens denn als eigentliche Reichserweiterung angesehen. Ihre Bewohner in den für uns nicht genau abgrenzbaren agri decumates (dem sog. „Zehntland“) werden an anderer Stelle in der „Germania“ von Tacitus ausdrücklich nicht den Völkern Germaniens zugerechnet, da - wie er schreibt - lauter unzuverlässige und aus Not unternehmungslustige Gallier den Boden in Besitz genommen hätten. ${ }^{13}$ Jedoch wollte Tacitus nicht etwa ein Verwaltungshandbuch verfassen, vielmehr sollten in literarisch anspruchsvoller Form und im Kontrast zwischen zivilisiertem Imperium und urwüchsigem Germanien die gesellschaftlichen und politischen Realitäten in ihrer Widersprüchlichkeit und mit den Differenzen zwischen Anspruch und Wirklichkeit entlarvt werden.

Der kritische historische Rückblick des Tacitus auf die Auseinandersetzungen zwischen Rom und Germanien, die aller Propaganda zum Trotz bis zu seiner Zeit nicht zu dem erhofften und erwarteten endgültigen Sieg über Germanien geführt haben, zeigt aber auch, dass er selber nach 90 Jahren in der Varusschlacht keineswegs eine entscheidende Zäsur sah, die ihr nach landläufiger, moderner Vorstellung weithin zugesprochen wurde und wird. Ein wichtiges Ereignis: ja, aber keine Niederlage, welche eine grundsätzliche Wende in der römischen Germanienpolitik eingeleitet hätte. Sein historischer Überblick schließt sowohl die vorausliegende als auch die Folgezeit mit ein. Dabei lässt er in der „Germania“ offen, was letztlich zur Aufgabe aller offensiven Bemühungen geführt hat und wer dafür verantwortlich war. Unausgesprochen bleibt auch, was er sich für die nahe Zukunft von dem neuen Kaiser Trajan erhofft, auch wenn bereits an dieser Stelle eine gewisse Skepsis erkennbar ist, ob ein entscheidender Sieg über die Germanen und ein verdienter Triumph tatsächlich erwartet werden können. Rund 10-20 Jahre später scheint allerdings die pessimistische Einschätzung der Ergebnisse römischer Germanienpolitik durch den Historiker angesichts der militärischen Unternehmungen des Kaisers Trajan noch grundsätzlicher geworden zu sein. Dessen offensives Vorgehen richtete sich ja vorrangig auf den Do-

\footnotetext{
${ }^{11}$ Pomp. Mela 3,25.

12 Sen. nat. quaest. 6,7,1; brev. vit. 4,5.

13 Tac. Germ. 29,3; vgl. auch 29,2 zu den Mattiakern: „... Denn das Ansehen des römischen Volkes hat die Anerkennung seiner Herrschaft über den Rhein, das heißt über die alten Grenzen hinaus vorgeschoben. So leben sie ihrem Siedlungsgebiet nach auf der germanischen Seite des Rheins, ihrer Mentalität und ihrem Empfinden nach jedoch zusammen mit uns.“
} 
nauraum mit Dakien und dann auf den Osten bis weit nach Mesopotamien. (vgl. Abb. 2) An den geschaffenen Fakten im Hinblick auf die Realisierung einer Germania war nicht mehr zu rütteln. In den „Annalen“ erfolgt daher eine grundlegendere Reflexion über die römische Germanienpolitik und ihre Wendungen, das Urteil ist präziser und deutlicher akzentuiert. Jetzt wird in historischer Rückschau der eigentliche Wendepunkt römischer Bestrebungen, das Gebiet der Germania magna bis zur Elbe dem Reich unmittelbar einzuverleiben, in der Abberufung des Germanicus als Befehlshaber vom germanischen Kriegsschauplatz durch Kaiser Tiberius Ende 16 n.Chr. und im glänzenden Triumph des Prinzen im folgenden Jahr fixiert. Jedoch schon damals waren nach Tacitus Abberufung und Triumph lediglich Folgen von Täuschung unter Errichtung einer Scheinfassade, und damals war seiner Meinung nach auch die letzte reale Gelegenheit zur Durchsetzung der Ziele im Raum der Germania magna in den von Augustus vorgegebenen Grenzen vertan worden. ${ }^{14}$ Hier also ist der Anfang vom Ende zu fixieren, und nicht wenige moderne Autoren sind dieser Ansicht des Tacitus gefolgt. Eine entscheidende historische Zäsur markiert jedenfalls die Varusschlacht auch im späten Urteil des Tacitus nicht. Zu einer solchen sollte sie in der Antike erst in der Folgezeit erklärt werden.

Bei Tacitus ist nach mehr als 100 Jahren in der Rückschau eine pessimistische Einschätzung der Ergebnisse römischer Germanienpolitik nach den Maßstäben der seit augusteischer Zeit propagierten Zielsetzungen unverkennbar. Es lässt sich also eine Entwicklung in seinem Urteil von der „Germania“ bis zu den „Annalen“ ausmachen, musste doch die Endgültigkeit des Status quo zur Kenntnis genommen und akzeptiert werden. Dabei geht es Tacitus bei seinem kritischen Urteil keineswegs um eine territoriale Ausweitung des Imperiums um jeden Preis, nicht um die Einforderung einer grundsätzlich auf Weltherrschaft ausgerichteten imperialen Politik. Vielmehr stellt er die römische Politik nach den Maßstäben altrömischer Werte, die vor allem im Begriff der virtus, aber auch in der senatorischen libertas ihren markanten Ausdruck finden, auf den Prüfstand; damit zugleich jedoch auch den Principat im Allgemeinen und das Handeln der einzelnen Principes im Besonderen.

Die politischen Ereignisse aber hatten in der Vergangenheit und haben auch in der Gegenwart - wie Tacitus aufzeigt - stets ihre zwei Gesichter: Zum einen die realen Vorgänge, Handlungen und die diesbezüglichen konkreten Zielsetzungen, die allerdings nur wenigen genau bekannt waren und für die sich auch kaum jemand interessierte bzw. mangels zuverlässiger Informationen interessieren konnte, die letztlich aber auch zu den arcana imperii, den verschwiegenen Geheimnissen der hinter den Kulissen Agierenden gehörten. Zum anderen die propagierten Versionen politisch brisanter Vorgänge, die publikumswirksame Verbreitung derselben, welche kaum in ihrer sachlichen Berechtigung kontrollierbar waren und deshalb umso bereitwilliger von der Öffentlichkeit wahrgenommen wurden. Sie waren es, die im Allgemeinen eine weit nachhaltigere Wirkung auf Zeitgenossen und Nachwelt ausübten als die politischen Vorgänge selber oder kritische und zweifelnde Äußerungen einiger intellektueller Skeptiker und Bedenkenträger. Umso sorgfältiger bemühte man sich in den Führungszirkeln darum, unter Ausnutzung der verfügbaren Mittel politische oder militärische Ereignisse und Entscheidungen im gewünschten Licht erscheinen zu lassen. Bereits in der römischen Republik hatte man dieses erkannt; Augustus hat dann dieses

\footnotetext{
14 Tac. ann. 1,3,5f.; 1,49,3-51; 1,55-72,1; 2,5-26; 2,41. - Besonders aufschlussreich sind die Kapitel 2,26 mit der Abberufung des Germanicus und der ihr unmittelbar vorangestellten Ansicht, dass man nicht zweifelte, dass man den Krieg würde beenden können, wenn man noch den nächsten Sommer hinzugäbe, sowie 2,41 zum Triumph des Germanicus 16 n.Chr. mit der Bemerkung: „Da es untersagt war, den Krieg zu Ende zu führen, nahm man ihn als beendet an.“ - Vgl. auch weiter unten.
} 
Instrument als erster meisterlich für seine Zwecke genutzt, und die Erben auf dem Kaiserthron sind ihm hierin gefolgt. Man sah also im Allgemeinen die Geschichte und die politischen Vorgänge so, wie sie präsentiert wurden; diejenigen aber, welche genauere und differenzierte Kenntnisse besaßen, waren gut beraten, sich in Urteilen zumindest über aktuelle Vorgänge zurückzuhalten. Je mehr aber ein übersättigtes Publikum im Verlauf der Zeiten gegenüber der Propagandaflut abzustumpfen drohte, desto gröber und übersteigerter fielen die Mittel aus, mit denen Wirklichkeit verpackt und verkauft wurde, dem auf der anderen Seite eine immer hemmungsloser agierende Schar willfähriger Adulatoren entsprach. Diese Differenz zwischen Propaganda und Realität, zwischen Schein und Wirklichkeit will Tacitus aufdecken. In der „Germania“ prangert er die in Triumphen gefeierten und nur scheinbar erfochtenen Siege an, im „Agricola“ dagegen das neidische Versagen eines Triumphes angesichts tatsächlicher Erfolge. Beides allerdings sind taciteische Deutungen, und wir haben zu fragen, ob sie denn ihrerseits wirklich die entlarvte Realität widerspiegeln. War Britannien, das bereits seit Claudius formell römische Provinz war, wirklich erstmals und entscheidend durch Agricola besiegt und für Rom gewonnen worden, was ihm legitimerweise einen Triumph hätte einbringen müssen, der ihm aber versagt wurde, und war Rom in Germanien, das selbst bis in domitianische Zeit noch keine formelle Provinz war, wirklich erfolglos gewesen und für immer gescheitert, obgleich in diesem Fall Triumphe gefeiert wurden?

\section{In Schlacht und Krieg besiegt -}

\section{Zur neuzeitlichen Bewertung der clades Variana}

Ob es überhaupt sinnvoll und sachgerecht ist, die römische Germanienpolitik in ihren Zielsetzungen und Ergebnissen auf einzelne punktuelle Zäsuren und Entscheidungen zu reduzieren, welche einen radikalen Kurswechsel anzeigen oder anzuzeigen schei-

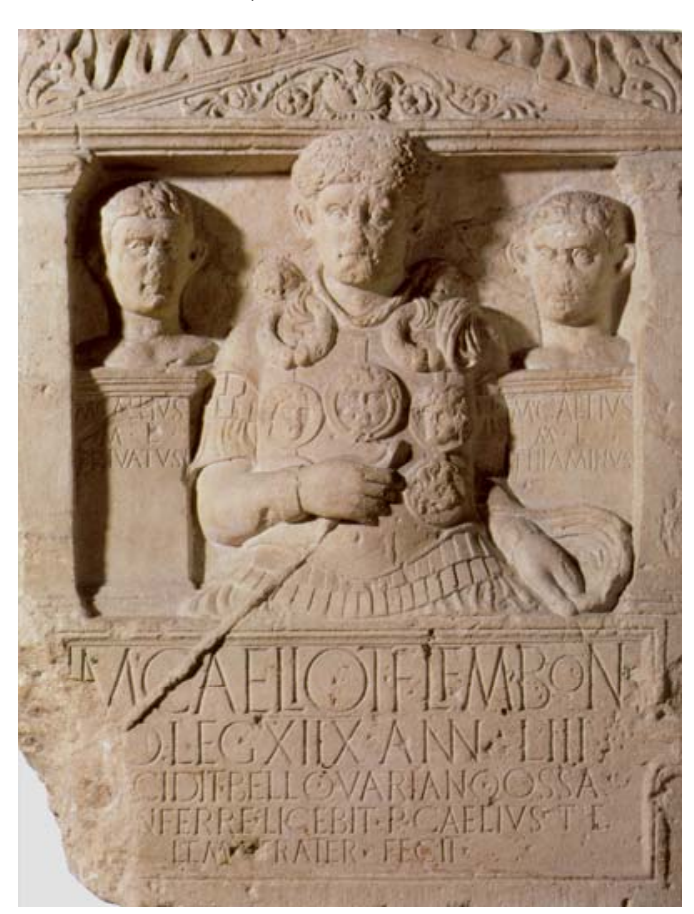

Abb. 4: Grabstein des M. Caelius aus Vetera bei Xanten nen, wird man in Frage stellen können. Angemessener dürfte es sein, auf den Prozess aufmerksam zu machen, gemäß dem sich Rom allmählich von den in augusteischer Zeit formulierten weitreichenden Ansprüchen auf ein Germanien bis zur Elbe gelöst und dafür an Rhein und Donau eine Grenzordnung geschaffen hat, ,welche ... bis zum Zusammenbruch der römischen Herrschaft im Westen im wesentlichen Bestand hatte.“15. Damit soll die Bedeutung einzelner Ereignisse und Entscheidungen nicht geleugnet werden. Dieses gilt auch für die Varusschlacht 9 n.Chr., auf deren historische Bewertung angesichts der aktuellen Diskussion nicht ganz verzichtet werden kann. Sie bildet als ein zweifellos schwerer Rückschlag für die römischen Ambitionen an der Nordfront des Imperiums den Ausgangspunkt jenes geschichtlichen Bogens, der seinen Abschluss in Ereignissen gegen Ende

\footnotetext{
${ }^{15}$ So schon mit Recht B.-J. WENDT, Roms Anspruch auf Germanien. Untersuchungen zur römischen Außenpolitik im ersten Jahrhundert n.Chr. Diss. Hamburg (mss.) 1960, I (Einleitung).
} 
des 1. Jahrhunderts fand. Bei den römischen Schriftstellern ist stets von der clades Variana die Rede, also von einer Niederlage wie manche andere auch; jedoch heißt es in der Inschrift des berühmten Caelius-Steines aus Xanten, dass der Centurio im „,varianischen Krieg“ (bello Variano) fiel. Also scheint Rom im Jahr 9 n.Chr., je nach Sicht der Dinge, eine Schlacht oder einen ganzen Krieg verloren zu haben, wobei allerdings die Singularität der Formulierung auf dem Caelius-Stein und der besondere Charakter dieser Quelle zu berücksichtigen wären. ${ }^{16}$ (Abb. 4)

Derzeit ist die spektakuläre Niederlage Roms gegen eine Koalition germanischer Stämme unter Führung des Cheruskers Arminius im Jahr 9 n.Chr. wieder einmal in aller Munde, gilt es doch, sich eines Ereignisses vor genau 2000 Jahren zu erinnern, das durch seine Rezeption in neuerer Zeit eine weitaus größere geschichtliche Wirkung nach sich gezogen hat als das zweifellos dramatische Schlachtgeschehen selber und seine unmittelbaren Folgen. Die Ausstellungstrilogie: „Imperium - Konflikt - Mythos“ „an den Originalschauplätzen“, wie es anspruchsvoll heißt, nimmt ihren Ausgangspunkt von der Varusschlacht, ${ }^{17}$ und auch die Deutsche Post hat das dreigeteilte Event verbreitet, und zwar mit einer 55 Cent-Marke, wie man stolz betont. (Abb. 5) Zu befürchten ist allerdings, dass die publikumswirksame Eröffnung der Ausstellungen in Kalkriese und Detmold durch die Bundeskanzlerin ein zumindest problematisches Geschichtsbild von einer durch eine einzige Schlacht begründeten oder auch geretteten deutschen Geschichte in den Köpfen der Zeitgenossen eher festigt als dass sie zur kritischen Reflexion über Ereignis und Wirkung anregt. ${ }^{18}$ Auch

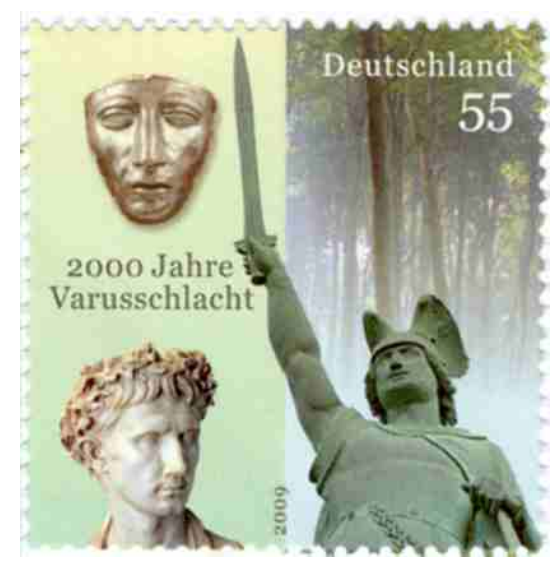

Abb. 5: Briefmarke 2000 Jahre Varusschlacht setzt nicht von ungefähr die vor wenigen Jahren eröffnete Dauerausstellung im Deutschen Museum in Berlin mit der Varusschlacht ein, was zumindest einer kritischen Kommentierung bedürfte, basiert doch die Gleichung ,germanisch = deutsch“ auf einer historischen Fiktion. ${ }^{19}$

Selbst die Frage nach den Germanen ist nicht so einfach zu beantworten, wie dies im populären Verständnis erscheint, zumal es bislang an einem allgemein akzep-

\footnotetext{
${ }^{16}$ Man wird daher die Formulierung „bello“ nicht pressen dürfen. Von größerem Interesse ist allerdings die Bezeichnung des „Krieges“ als desjenigen des Varus, was zumindest ungewöhnlich ist, wurden in Rom doch Kriege im Allgemeinen nach den Gegnern benannt. Die Varus-Niederlage wäre somit unter die bella Germanica einzureihen.

${ }^{17}$ Vgl. dazu den monumentalen, dreibändigen Katalog zu den Ausstellungen in Haltern, Kalkriese und Detmold: 2000 Jahre Varusschlacht: Imperium, Konflikt, Mythos, hrsg. vom LWL-Römermuseum, von der Varusschlacht im Osnabrücker Land/Museum und Park Kalkriese und vom Landesverband Lippe (Stuttgart 2009). - Eine kritische Beleuchtung der Beiträge zeigt, dass die Diskussion um die römische Germanenpolitik, den Ort der Varusschlacht und die Rezeption des Geschehens vor allem in der Neuzeit keineswegs an ihr Ende gelangt ist.

${ }^{18}$ Allerdings sollte auch nicht übersehen werden, dass man sich bei der Ausstellungstrias durchaus erfolgreich darum bemüht hat, jegliche Einbettung der kriegerischen Konflikte in nationale oder gar nationalistische Anschauungen und Denkweisen zu vermeiden. Dem Anliegen der veranschaulichten historischen Erinnerung entsprechend sollen die Varusschlacht und ihre Rezeption vielmehr über die konkreten geschichtlichen Zusammenhänge hinaus Ausgangs- und Bezugspunkte sein für eine zeitlose Anmahnung friedlicher Koexistenz der Völker, was sich gerade die „Friedensstadt Osnabrück“ zu ihrem besonderen Anliegen gemacht hat.

${ }^{19}$ Vgl. dazu: Zur Geschichte der Gleichung ,germanisch-deutsch“, hrsg. von H. BECK, D. GEUENICH, H. STEUER und D. HAKELBERG (Berlin/New York 2004) (=Ergänzungsbände RGA 34).
} 
tierten, interdisziplinären Begriff dessen, wer und was unter „Germanen“ und „germanisch“ zu verstehen ist, fehlt. ${ }^{20}$ Dass nämlich ein sogenanntes „Freies Germanien“ - was im Übrigen eine ideologisch unterfütterte Bezeichnung erst der Neuzeit ist ohne weiteres als ein ethnisch dauerhafter und einheitlicher Großraum lediglich postuliert wird, nicht aber nachgewiesen werden kann, dass angesichts des Fehlens eines umfassenden germanischen Gemeinschaftsbewusstsein auch nicht von einer germanischen „Nation“ die Rede sein kann, wurde und wird in nationaler Emphase bewusst oder unbewusst ignoriert, oder es wird im laienhaften Denken und in verbreiteten historischen Alltagsvorstellungen ein dauerhaftes, sich stammbaumartig entfaltendes Volkstum einfach als naturgegeben vorausgesetzt. Ein Kampfgeschehen, welches in populärer Vorstellung vereinfachend zu einer Schlacht verdichtet wird, liefert in der Tat einen griffigen und zugleich spektakulären Ansatzpunkt für eine historische Erinnerung insbesondere bei denjenigen, die meinen, sich in einer eigenen, ungebrochenen Tradition mit den germanischen Siegern des Jahres 9 n.Chr. zu befinden und bei denen sich ein verinnerlichtes, aus nationaler Emphase gespeistes Selbstwertgefühl mit einer gehörigen Portion Heimatstolz mischt.

Die weltgeschichtliche Bedeutung der Varusschlacht in Frage zu stellen, kontrastiert allerdings mit einem verbreiteten Geschichtsbild, das mit diesem Ereignis das grundsätzliche Scheitern Roms in Germanien verbindet. ${ }^{21}$ Gelegentlich werden noch die Feldzüge des Germanicus 14-16 n.Chr. mit in die Analyse einbezogen und wird dieses Scheitern eben an der Abberufung des Germanicus vom germanischen Kriegsschauplatz festgemacht. ${ }^{22}$ So einfach scheinen indes die Dinge nicht zu liegen. Schon Theodor Mommsen stellte 1885 fest: „Die Varusschlacht ist ein Rätsel, nicht militärisch, aber politisch, nicht in ihrem Verlauf, aber in ihren Folgen.“ Als er diesen Satz in seiner „Römischen Geschichte“ formulierte, ${ }^{23}$ war die allgemeine Begeisterung um Arminius bzw. Hermann den Cherusker und über seine historische Tat bzw. Taten noch in vollem Gang. 10 Jahre zuvor war das Hermannsdenkmal im Teutoburger Wald bei Detmold von Kaiser Wilhelm I. eingeweiht worden. Es war damit zu einem zeitlosen Erinnerungsund Mahnmal des noch jungen deutschen Reiches erklärt worden. (Abb. 6)

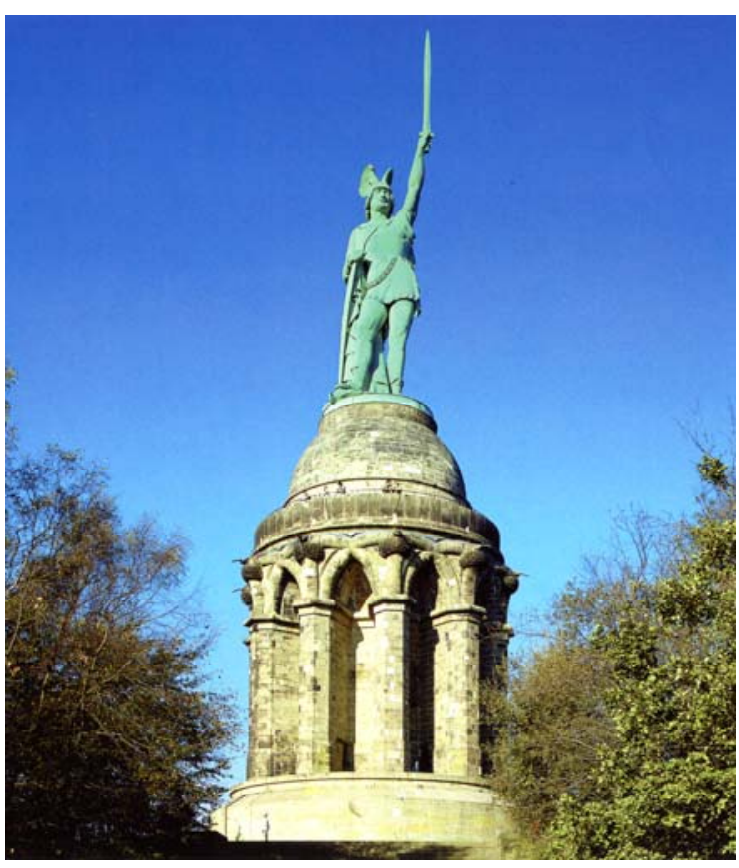

Abb. 6: Hermannsdenkmal

Eine maßgebliche Rolle bei der

Hochschätzung von historischer Tat und Person spielte nicht nur im laienhaften Ge-

\footnotetext{
${ }^{20}$ TIMPE, in: RGA ${ }^{2}$ (Anm. 4) 2 ff.

${ }^{21}$ Kritisch dazu R.WIEGELS, in: DERS. (Hrsg.), Die Varusschlacht - Wendepunkt der Geschichte? (Stuttgart 2007).

${ }^{22}$ Vgl. dazu besonders die Analyse von G.A. LeHMANN, Das Ende der römischen Herrschaft über das „westelbische“ Germanien: Von der Varus-Katastrophe zur Abberufung des Germanicus Caesar 16/17 n.Chr., in: R. WIEGELS / W. Woesler (Hrsg.), Arminius und die Varusschlacht. Geschichte - Mythos Literatur (Paderborn/München/Wien/Zürich ${ }^{3}$ 2003) 123-141.

${ }^{23}$ Th. Mommsen, Römische Geschichte, Bd. V: Die Provinzen von Caesar bis Diokletian (Berlin 1885 $={ }^{4} 1904=$ Ndr. München 1976) 50 .
} 
schichtsverständnis der Nachruf des Tacitus auf Arminius, in welchem er diesen zum „Befreier Germaniens“ erklärte. Wohl kaum eine andere Würdigung einer Person in der antiken Literatur hat eine derartige, Jahrhunderte überdauernde Langzeitwirkung insbesondere im deutschen Raum entfaltet wie diejenige, welche Tacitus dem Sieger im Teutoburger Wald bei dessen Tod 21 n.Chr. angedeihen ließ, wo es heißt: „Im Übrigen hatte Arminius, der nach dem Abzug der Römer und der Vertreibung Marbods nach der Königsherrschaft strebte, den Freiheitssinn der Volksgenossen gegen sich, und als man mit Waffengewalt vorging, kämpfte er mit wechselndem Glück und fiel durch die Hinterlist seiner Verwandten: Er war ohne Zweifel der Befreier Germaniens (liberator haud dubie Germaniae), der nicht wie andere Könige und Heerführer das römische Volk in seinen Anfängen, sondern das Imperium in seiner größten Blüte herausgefordert und in den Schlachten zwar mit wechselndem Erfolg (gekämpft hatte), im Krieg aber unbesiegt (geblieben war)“ ${ }^{24}$ Der erste Teil dieses Nachrufs konnte als Mahnung zu nationaler Einigkeit ausgelegt, der zweite als das Recht auf eine bedingungslos anzustrebende und zu verteidigende nationale Freiheit verstanden werden. Seit Generationen wurde und wird diese zweifellos bemerkenswerte und ungewöhnlich positive Würdigung eines erfolgreichen Gegners aus der Feder eines Römers immer wieder als Beleg für die geschichtswirksamen Taten des Cheruskerfürsten herangezogen und dieser emphatisch als Retter Germaniens vor römischer Überfremdung gefeiert. In der Tat ist der spektakuläre militärische Erfolg in einem einzigen großen, wenn auch über 3 oder 4 Tage dauernden Kampfgeschehen im Herbst des Jahres 9 n.Chr. im saltus Teutoburgiensis nicht zu leugnen. Er legte es nahe, in ihm jenen schon angesprochenen historischen Wendepunkt zu erkennen, mit dem das römische Reich in seine Schranken gewiesen und die Freiheit Germaniens bewahrt wurde. Auf Rom bezogen glaubte man allzu gerne aus dem Urteil den Schluss ziehen zu können: Rom hatte nicht nur eine Schlacht, sondern einen Krieg verloren.

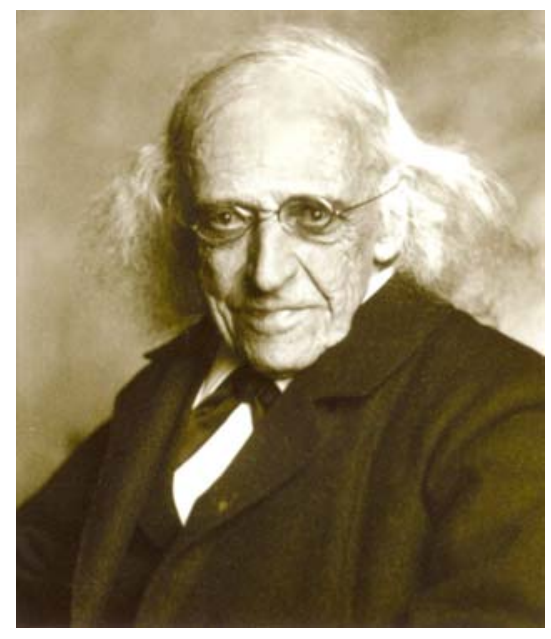

Abb. 7: Theodor Mommsen (1817-1903)

Im Banne der nationalen Zeitströmung hatte auch Mommsen geurteilt. (Abb. 7) In einem Vortrag, den er zwei Monate nach der Reichsgründung im März 1871 in Köln hielt und der durch seine Veröffentlichung rasch weite Verbreitung und Beachtung erfuhr, kommt er zu dem Schluss, dass die neue Monarchie in Rom erobern wollte, ja musste. Entsprechend seinem kritischen Augustusbild unterstreicht Mommsen, dass die Monarchie zur Legitimation ihres Systems militärische Eroberungen benötigt hätte. Ziel war nach Mommsen die Elbe, der „eiserne Ring, der Großdeutschland umklammern sollte. “25 6 n.Chr. war dieses Ziel nach dem erneuten Vorstoß des Tiberius bis zur Elbe nahezu erreicht, als der Gegenschlag der Nationen alles in Frage stellte und die Varus-Katastrophe zu einem „Wendepunkt der Weltgeschichte“ führte und der Plan der Eroberung Germaniens aufgegeben wurde. ${ }^{26}$ Aber ganz blieb Mommsen nicht bei dieser Ansicht. Zwar betont er auch

\footnotetext{
${ }^{24}$ Tac. ann. 2,88,2.

${ }^{25}$ TH. Mommsen, Die germanische Politik des Augustus. Vortrag gehalten im Wiss. Verein Köln am 23. März $1871=$ Ndr. in: TH. Mommsen, Reden und Aufsätze $(1905=$ Ndr. Hildesheim/New York 1976) 316-343, hier 337.

${ }^{26}$ Ebd. 341.
} 
in seiner „Römischen Geschichte“, dass der eigentliche Kriegsplan Roms von vornherein auf die Errichtung einer römischen Provinz Germania bis zur Elbe zielte. Aber im Gegensatz zum Vortrag markiert jetzt nicht die Varusschlacht, sondern die Abberufung des Germanicus vom germanischen Kriegsschauplatz Ende 16 n.Chr. den eigentlichen „Wendepunkt der Völkergeschicke“, der in Germanien nach der „Hochflut“ die „Ebbe“ eingeleitet habe. ${ }^{27}$ Damit ist das Problem zwar zunächst nur verschoben, aber doch deutlich von der Varusschlacht als entscheidender Zäsur auf die schon von Tacitus in den Annalen vertretene epochale Entscheidung verlagert. In der Bilanz allerdings konnte so oder so nur ein Scheitern der römischen Germanienpolitik unter den Prämissen der augusteischen Zeit konstatiert werden.

Unabhängig aber vom Ergebnis lag gemäß der nachdenklichen und zum Nachdenken auffordernden Feststellung Mommsens das eigentlich Rätselhafte und historisch Bedeutungsvolle der Varusschlacht nicht im militärischen Geschehen als solchem und entgegen den modernen, mit unverminderter Heftigkeit geschlagenen „Schlachten um die Schlacht im Teutoburger Wald“ auch nicht in deren Lokalisierung. Denn abgesehen davon, dass Mommsen dieses Rätsel der Örtlichkeit für gelöst erachtete, ${ }^{28}$ war er ohnehin der Ansicht, dass diese Frage nicht so wichtig sei, als dass es sich darüber zu verzanken lohne. Man ist gut beraten, sich nicht an diesen „Schlammschlachten“, die auch aktuell wieder toben und begierig von Fernsehen, Presse oder in Internetforen aufgegriffen werden, zu beteiligen. Der Sache dienen sie im Allgemeinen nicht.

\section{Die Varusschlacht und der Triumph des Germanicus im historischen Urteil}

Um die historische Bedeutung der Varusschlacht und ihrer Folgen gemäß dem Urteil und den Einschätzungen der Zeitgenossen einordnen zu können, ist ein Zurück zu den Quellen unverzichtbar. Dabei ist die zeitliche Nähe oder Ferne der Autoren zum Ereignis selber von erstrangiger Bedeutung.

Unser wichtigstes, gleichsam offizielles zeitgenössisches Zeugnis sind die inschriftlich überlieferten Res gestae divi Augusti, der gegen Ende seines Lebens verfasste oder zumindest redigierte Tatenbericht des Augustus, eine Selbstdarstellung, die kurz nach seinem Tod im Herbst 14 n.Chr. über das ganze Imperium verbreitet wurde. In ihm rühmt sich der Princeps, die Grenzen aller Provinzen, denen Völkerschaften benachbart waren, welche unserem Befehl (noch) nicht gehorchten, erweitert zu haben. Weiter heißt es: „Die gallischen und spanischen Provinzen und ebenso Germanien, soweit sie der Ozean von Cadiz bis zur Elbmündung umschließt, habe ich unterworfen“. Es folgt der Hinweis auf die Unterwerfung der Alpen von der Adria bis zum Tyrrhenischen Meer, auf die stets gerechte Kriegsführung und insbesondere auf die Flottenexpedition des Jahres 5 n.Chr. in bislang unbekannte Gegenden entlang der jütländischen Küste. ${ }^{29}$ Man hat vermutet, dass sich hier hinter einer ,gewundenen Formulierung“ bereits eine „peinliche Diskrepanz zwischen Anspruch und Wirklichkeit“ verberge $^{30}$, was man allerdings so nicht unbedingt teilen muss. Es werden hier gewissermaßen geographische Eckpunkte der römischen Herrschaft fixiert. Nichts deutet jedenfalls darauf hin, dass auf diese Weise bereits ein Verzicht auf ein Germa-

\footnotetext{
${ }^{27}$ TH. MOMMSEN, Römische Geschichte (Anm. 23) 53.

${ }^{28}$ TH. Mommsen, Die Örtlichkeit der Varusschlacht. Sitzber. Kgl. Akad. Wiss. 1885 (mit Zusätzen als Separatum) (Berlin 1885) (= Ndr. in: TH. MommSEN, Gesammelte Schriften 4,1 [Berlin 1906] 200246).

${ }^{29}$ Aug. R.g. 26.

${ }^{30}$ Nesselhauf, Tacitus (Anm. 5) 235. Ähnlich auch R. SymE, in: The Cambridge Ancient History Bd. X : The Augustan Empire (44 B.C. - A.D. 70) (Cambridge 1934 = Ndr. mit Korr. 1966) 376.
} 
nien bis zur Elbe und damit eine grundlegende Anerkennung der Folgen der Varusschlacht angedeutet würden. Unabhängig davon, wieweit der Anspruch auf die Germania magna aktuell den realen Gegebenheiten entsprach, blieb er ohne Zweifel aufrecht erhalten und bezog sich auf den germanischen Bereich östlich des Rheins und nördlich der Donau bis zur Elbe, welchen Fluss zu überschreiten Augustus ausdrücklich verboten hatte. Auch der eigenhändig von Augustus kurz vor seinem Tod einem Schriftstück, das die Machtmittel des Staates verzeichnete und sein Nachfolger im Senat verlesen ließ, zugefügte Rat, man solle das Reich in seinen bestehenden Grenzen belassen, kann für Germanien nur das Gebiet bis zur Elbe einschließen. ${ }^{31}$ Der Rückblick auf rund 30 Jahre römischer Eroberungspolitik östlich des Rheins und ihre in Stein gemeißelte reichsweite Publikation beinhalteten somit auch eine Verpflichtung für den Nachfolger, den auf diese Weise festgelegten Ansprüchen durch das eigene Handeln gerecht zu werden. Konkrete Maßnahmen wie die Erhöhung der Zahl der Legionen an der Rheinfront auf acht nach der Varuskatastrophe und ihre Unterstellung unter ein einheitliches Kommando an Germanicus noch durch Augustus 13 n.Chr. unterstreichen denn auch deutlich den Willen und die Absicht, die alten Ziele, wenn auch nicht unmittelbar, so doch mittelfristig weiter zu verfolgen.

Eben dieses erwartete auch die Öffentlichkeit, soweit wir es der zeitgenössischen Dichtung und Literatur entnehmen können. Ovid hat bereits in den Büchern 3 und 4 seiner „Tristien“ aus den Jahren 10 und 11 n.Chr. wiederholt die Erwartung geäußert, dass schon bald Triumphe über Germanien vermeldet und das rebellische und wilde Germanien sich unterwerfen würde. In der Sprache des Dichters heißt es, dass man in naher Zukunft von erfüllten Gelübden an Iupiter hören würde und davon, dass das aufrührerische Germanien endlich sein trauriges Haupt dem großen Feldherrn (Tiberius) zu Füßen legen würde. ${ }^{32}$ An anderer Stelle prophezeit er: „Jetzt mag vor den Caesaren das wilde Germanien, wie der ganze Erdkreis, besiegt liegen mit gebeugtem Knie... So wird das ganze Volk die Triumphe schauen können ... Mit aufgelösten Haaren wird auch Germania präsentiert, und sie sitzt trauernd zu Füßen des unbesiegten Feldherrn; mutig bietet sie den Nacken dem römischen Beil dar, trägt Ketten an der Hand, die vorher Waffen trug. “33 Auch in den Briefen vom Schwarzen Meer äußert Ovid die Erwartung auf einen baldigen Triumph über ein treuloses und grausames Germanien und bildhaft über den Rhein. ${ }^{34}$ Die 21. imperatorische Akklamation des Augustus zusammen mit der 7. des Tiberius im Jahr 14 n.Chr. und die 1. Akklamation des Germanicus wohl noch zu Lebzeiten des Augustus wurden wahrscheinlich alle wegen Erfolgen in Germanien angenommen, womit die Kontinuität eines siegreichen Vorgehens auch nach außen betont wurde. ${ }^{35}$

Im Werk des Geographen Strabo, das um 19 n.Chr. abgeschlossen wurde, gipfeln die Kriegszüge des Germanicus in dessen ausführlich beschriebenen Triumph 17

\footnotetext{
${ }^{31}$ Tac. ann. 1,11; vgl. dazu auch Cass. Dio 56,35,5. - Bemerkenswert ist die Ansicht des Strabo 7,1,4 (= p. 291 C), wonach der Krieg hätte schneller beendet werden können, wenn Augustus seinen Feldherren nicht verboten hätte, die Elbe zu überschreiten.

${ }^{32}$ Ov. trist. 3,12,45-48.

${ }^{33}$ Ov. trist. 4,2,1 f.; $19 \mathrm{ff}$.

${ }^{34}$ Ov. Pont. bes. 2, 8,47; 3,4, 87 f.; 95-97.

${ }^{35}$ Die 21. Akklamation des Augustus ist nur bei Tac. ann. 1,9 und Cass. Dio 52,41,4 überliefert; die 7. des Tiberius u.a. durch Münzen wohl noch aus der Zeit des Augustus, die in Lugdunum/Lyon geprägt wurden (RIC $\mathrm{I}^{2}$ Tib. 1 f.). Das Datum der ersten Akklamation des Germanicus ist in der Forschung umstritten, es schwankt zwischen 9, 11 (so Cass. Dio 56,25,2) und 12/13 n.Chr., setzt aber doch wohl voraus, dass Germanicus im Besitz des imperium proconsulare war, was kaum bereits zu einem Zeitpunkt erfolgt sein wird, als Tiberius noch das Kommando am Rhein führte. Dieses spricht für den späten Ansatz.
} 
n.Chr., welcher den Eindruck der Einlösung einer alten und über den Tod des Augustus hinausweisenden Verpflichtung anzeigt. Zugleich tritt die Varusniederlage als eine Episode einer lang andauernden Auseinandersetzung weitgehend zurück. Der Anspruch Roms auf das Gebiet der Germania bis zur Elbe wurde danach erneut und nachdrücklich untermauert, daran hat auch die Varusschlacht nichts geändert. ${ }^{36}$ Noch ausführlicher argumentiert der Zeitgenosse Velleius Paterculus in seinem Abriss über die römische Geschichte bei der Behandlung der Varusschlacht, wenngleich er keinen lückenlosen Bericht geben will. Stattdessen kündigt er eine eigene Monographie über dieses Ereignis an, die aber wohl nie geschrieben wurde. ${ }^{37}$ In unserem Zusammenhang von Bedeutung sind die von ihm geschilderten politischen und militärischen Reaktionen in Rom auf die Niederlage, die dazu führten, dass bis zum Jahre 12 n.Chr., als Tiberius vom erneuten Kommando in Germanien nach Rom zurückkehrte, Germanien schneller als erwartet verwüstet worden war und sich der Feldherr eigentlich einen weiteren Triumph verdient hätte. ${ }^{38}$ Das ist natürlich Panegyrik. Aber auch Velleius geht von einer kontinuierlichen Fortsetzung und Verfolgung augusteischer Zielsetzungen aus; die Varusschlacht ist und bleibt eine - wenn auch dramatische - Episode. Tiberius hat danach die entscheidenden Weichen zur Wiedergewinnung der verlorenen Gebiete gestellt, Germanicus nur noch den Schlussstrich gezogen. In einer offiziellen Verlautbarung wird Germanicus jedoch anlässlich seines Triumphes 17 n.Chr. als „domitor Germaniae“, als „Bezähmer Germaniens“ charakterisiert. $^{39}$ (Abb. 8)

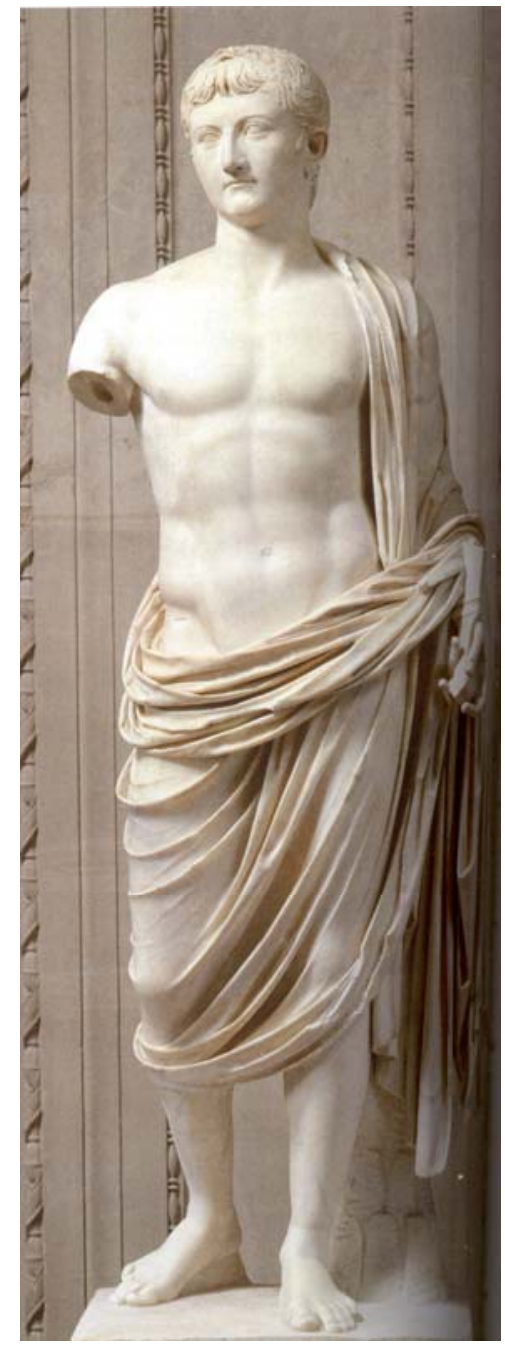

Abb. 8: Statue des Germanicus aus Gabii (Louvre Paris)

Mehr als 80 Jahre später hat sich dann Tacitus in seinen Annalen ausführlich mit den Vorgängen in Germanien und den Kriegszügen des Germanicus zur Zeit des Tiberius auseinandergesetzt.

Die Situation in Germanien am Ende des Jahres 16 n.Chr. beschreibt der Historiker wie folgt: „Man bezweifelte nicht, dass die Feinde ... den Beschluss fassen würden, um Frieden zu bitten, und dass man den Krieg beenden könne, wenn man noch den nächsten Sommer hinzugäbe. Tiberius aber mahnte wiederholt in Briefen, Germanicus solle zu dem zuerkannten Triumph (nach Rom) zurückkehren: Es habe schon genug Erfolge und Unglücksfälle gegeben. Erfolgreich und groß seien seine Schlachten; er möge aber auch daran denken, welche schwerwiegenden und furchtbaren Schäden Wind und Wellen, ohne Schuld des Feldherrn, verursacht hätten.... Germanicus ... begriff, dass das vorgetäuscht war und ihm aus Neid die bereits erworbene Ehre entzogen werden (sollte)“ ${ }^{40}$ Und anlässlich des Triumphes notiert Tacitus:

\footnotetext{
${ }^{36}$ Strabo 7,1,4 (= p.292 f. C).

${ }^{37}$ Vell. 2,117-119.

${ }^{38}$ Vell. 2, 120-122,2.

${ }^{39}$ Siehe dazu weiter unten.

40 Tac. ann. 2,26.
} 
„Da es untersagt war, den Krieg zu Ende zu führen, nahm man ihn als beendet an“. ${ }^{41}$ Insoweit basierte also auch dieser Triumph wie die folgenden des Caligula oder Domitian auf einer politischen und militärischen Fiktion, die Tacitus aber nicht dem Caesar Germanicus, sondern dem Princeps Tiberius anlastet. Mit ihm wurde das gemessen an den Absichten und unternommenen Anstrengungen letztlich negative Ergebnis der Feldzüge nur verschleiert und nach bewährtem Muster in einen Sieg umgedeutet. Folglich wird dem Arminius auch nicht in erster Linie wegen seines Erfolges im Teutoburger Wald 9 n.Chr., sondern wegen seines letztlichen Standhaltens gegen Germanicus in tiberischer Zeit geschichtliche und bis heute folgenreiche Anerkennung gezollt.

Nicht wenige Historiker sind in der jüngeren Vergangenheit dem Urteil des Tacitus gefolgt und haben die letztendliche Aufgabe aller Eroberungspläne der Gebiete bis zur Elbe ebenfalls mit der Abberufung des Germanicus verbunden. ${ }^{42}$ Die von Kaiser Tiberius in diesem Zusammenhang getroffene Feststellung, man solle die Germanen ihren eigenen Streitigkeiten überlassen, konnte als authentische Absage Roms an ein Germanien bis zur Elbe angesehen werden. Das Urteil über absehbare innergermanische Konflikte war aus der Erfahrung gewonnen und sollte sich in der Tat auch für die Zukunft als zutreffend erweisen. Die schon bald ausbrechenden Kämpfe zwischen Markomannen und Cheruskern, aber auch die labilen Verhältnisse innerhalb der Stammesaristokratien mit den um die Führung rivalisierenden Adelsfraktionen legen hiervon beredtes Zeugnis ab. Es mag als ein Paradoxon erscheinen, wenn man somit den letzten Grund für die Aufgabe eines offensiven Vorgehens gegen die bis zur Elbe siedelnden Germanen nicht in ihrer bedrohlichen Stärke, sondern gerade in ihrer Schwäche erkennt.

$\mathrm{Ob}$ es aber gerechtfertigt ist, erneut eine grundsätzliche Zäsur römischer Germanienpolitik gewissermaßen punktuell an einer einzigen Entscheidung, wenngleich nicht der Varusschlacht, festzumachen, erscheint mehr als fraglich. Wie die Niederlage im Teutoburger Wald, so entfaltete zweifellos auch die Abberufung des Germanicus eine nachhaltige Wirkung und hatte eine aktuelle Neuorientierung der römischen Germanienpolitik zur Folge, aber bedeutete sie die grundsätzliche Aufgabe aller entsprechenden, an den augusteischen Zielsetzungen orientierten Pläne und Ansprüche, und dies für alle Zukunft? Immerhin verwies der Princeps Tiberius auch darauf, man könne, wie schon in der Vergangenheit, so auch in der Zukunft mehr durch planende Vernunft und damit Diplomatie erreichen als durch militärische Gewalt (plura consilio quam vi). ${ }^{43}$ Damit wird auf andere Mittel, nicht aber eine veränderte Zielsetzung abgehoben. ${ }^{44}$ Ob der Kaiser selber daran geglaubt hat, steht dahin. In der Praxis ist jedenfalls nicht zu erkennen, dass er ernsthafte Anstrengungen unternommen hätte, ein Germanien bis zur Elbe dem römischen Reichsgebiet anzugliedern. Die konkreten Maßnahmen an der germanischen Front in tiberischer Zeit, die vor allem

\footnotetext{
${ }^{41}$ Tac. ann. 2,41,2.

${ }^{42}$ Insbesondere in der jüngeren Literatur scheint sich diese Ansicht verbreitet durchzusetzen, die sich allerdings schon bei Mommsen findet, siehe dazu schon weiter oben bes. mit Anm. 26. Vgl. auch WENDT, Roms Anspruch (Anm. 15) bes. 38 ff. und G.A. LEHMANN, Zum Zeitalter der römischen Okkupation Germaniens: neue Interpretationen und Quellenfunde. Boreas 12, 1989, 207-230, bes. 227 ff.; DERS., Ende (Anm. 22).

${ }^{43}$ Tac. ann. 2,26,3.

${ }^{44}$ Nach Tac. ann. 2,26,4 hatte Tiberius zudem Drusus mittelfristig als Nachfolger seines Vaters Germanicus in Germanien vorgesehen. Der Bericht des Tacitus suggeriert, dass dieser Plan eigentlich gar nicht bestand und nur als ein Vorwand für die Abberufung des Germanicus diente. Ob dieses so der Fall war, lässt sich heute nicht mehr ermessen. Der frühe Tod des Drusus machte ohnehin diesbezügliche Pläne hinfällig, gleich ob sie überhaupt und wie lange sie bestanden haben mögen.
} 
den Ausbau einer Sicherheitszone am Rhein belegen, weisen vielmehr im militärtaktischen Bereich auf neue Akzentsetzungen. ${ }^{45}$ Andererseits war es aber aus innenpolitischen Gründen weder geboten noch opportun, eine Preisgabe der alten Ansprüche öffentlich einzugestehen. Die nach der Varuskatastrophe erhöhte Zahl an Legionen an der germanischen Front auf insgesamt acht - nahezu ein Drittel der gesamten Reichsarmee - blieb erhalten, die ungewöhnliche Einrichtung von Militärbezirken - wohlgemerkt auf linksrheinischem, gallischem Gebiet - unter den Bezeichnungen exercitus Germanicus superior bzw. inferior und nicht als provinciae des römischen Volkes signalisierten zumindest für die Öffentlichkeit den unverändert aufrecht erhaltenen Anspruch, dessen Einlösung man der Zukunft überlassen mochte. Diese Öffentlichkeit dürfte mangels genauer Informationen über die tatsächlichen Vorgänge die offiziell verbreiteten Versionen für bare Münze gehalten haben, Skeptiker und intimere Kenner der Lage werden sich dabei beruhigt oder darin sogar ein legitimes Mittel zur Beeinflussung der öffentlichen Meinung gesehen haben, nur wenigen war es allerdings ohnehin möglich, hinter die Kulissen bis zu den arcana imperii vorzudringen, was auch Tacitus als hinderlich für eine sachgerechte Geschichtsschreibung ausdrücklich beklagt.

Am 26. Mai 17 n.Chr. feierte Germanicus in Rom einen glänzenden Triumph „über Cherusker, Chatten und Angrivarier sowie die anderen Stämme, die (das Land) bis zur Elbe bewohnen“." (Abb. 9) In dieser verbindlichen Formulierung wird ungeachtet des tatsächlich Erreichten der seit der Zeit des Augustus festgelegte Anspruch Roms auf eine römische Germania magna erneut befestigt. Wiederum wird die Elbe als Ziel, aber auch als Grenze römischen Herrschaftsanspruchs und unmittelbarer politischer Ambitionen

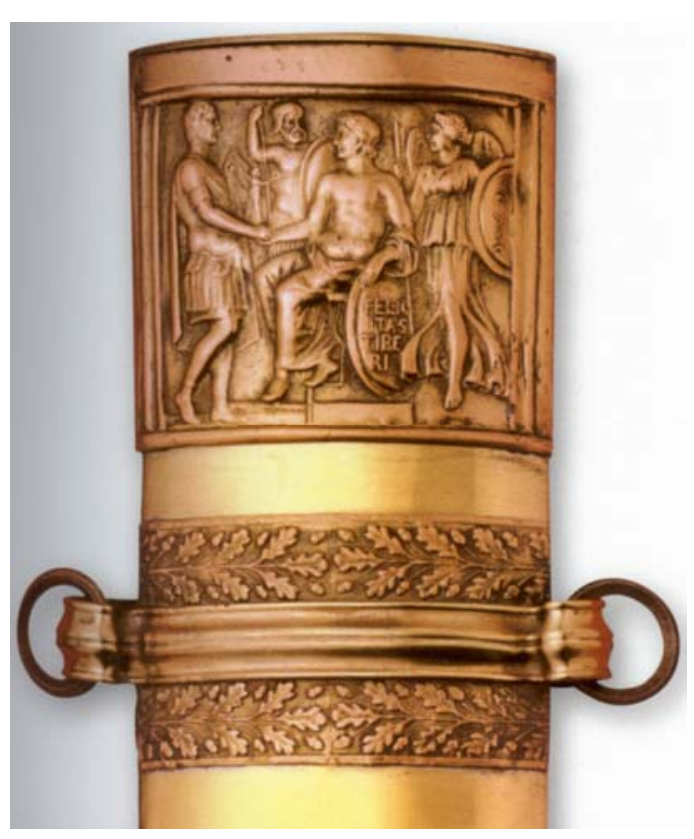

Abb. 9: Sogenanntes Schwert des Tiberius Mundblech fixiert. Dabei sollten nicht moderne Vorstellungen von flächigen Reichsgrenzen substituiert werden. Eine einheitliche Erfassung der Bevölkerung in genau fixierten Gebieten hätte nur über die Etablierung einer Provinzverwaltung erfolgen können. Aber gerade das unterblieb, und zwar aus gutem Grund. Herrschaft sollte und konnte auch nicht in erster Linie über ein bestimmtes Territorium, sondern nur über die allerdings nicht unbedingt fest gefügten Personenverbände und Stämme und mit Hilfe von deren Führungseliten erfolgen. Ihre Unterstützung galt es mit Anreizen oder auch mit Gewalt zu gewinnen, aber gerade das war angesichts labiler Herrschaftsstrukturen in den vom Adel geführten

\footnotetext{
${ }^{45}$ Aktuelle Forschungsergebnisse insbesondere der Archäologie legen es nahe, die konkreten politischen und militärischen Maßnahmen Roms an seiner Nordfront erneut umfassend zu untersuchen, worauf an dieser Stelle nur hingewiesen werden kann.

${ }^{46}$ Tac. ann. 2,41,2; vgl. Oros. hist. 7,4,3. - Siehe auch die inschriftlich überlieferten Festkalender von Ostia und Amiternum (Inscr. It. XIII/1 184 f.; CIL IX 4192); ferner Strabo 7,1,4 (= p.291 f.); Vell. 2,129,2: Germanicus als domitor Germaniae tituliert; Suet. Cal. 1,1. - Dazu u.a. D. TIMPE, Der Triumph des Germanicus. Untersuchungen zu den Feldzügen der Jahre 14-16 n. Chr. in Germanien (Bonn 1968) passim.
} 
Stammesgesellschaften prekär und hatte ein den Gegebenheiten entsprechend differenziertes politisches und diplomatisches sowie militärisches Vorgehen zur Folge. Mögen auch die großen Ziele gleich geblieben sein, so wurden doch die Mittel, diese zu erreichen, sehr überlegt den jeweiligen Gegebenheiten angepasst. Pointiert formuliert ging es Rom nicht in erster Linie um Beherrschung von Landmassen, sondern von Personen. Im Triumphalbeschluss für Germanicus ist daher von konkreten Stämmen und namenlosen nationes die Rede, nicht aber von einer Germania. ${ }^{47}$ Die Elbe markierte eine Grenze direkter römischer Interessen, dass sie als Flussgrenze von besonderem militärischem Nutzen war, darf man allerdings bezweifeln. ${ }^{48}$

Etwas anders gewichtet der Ehrenbeschluss des Senats nach dem Tod des Germanicus 19 n.Chr. dessen Leistungen in Germanien, wo es gemäß dem Text in der sogenannten Tabula Siarensis - einer Bronzetafel, die erst vor wenigen Jahrzehnten im südlichen Spanien geborgen wurde - heißt, dass drei Ehrenbögen zum Andenken an den Verstorbenen errichtet werden sollen, einer im Osten des Reiches am Amanos-Pass, der zweite in besonderer Größe am Rhein und der dritte im Circus Flaminius in Rom. (Abb. 10) Letzterer solle mit einer monumentalen Inschrift versehen werden, in der es u.a. heißt, dass Senat und Volk von Rom dieses Denkmal errichtet und geweiht haben zum Andenken an Germanicus Caesar, da dieser, „nach Besiegung der Germanen im Kriege und ihrer (...) Zurücktreibung von Gallien, nachdem ferner die Feldzeichen zurückgewonnen wurden und Rache genommen wurde

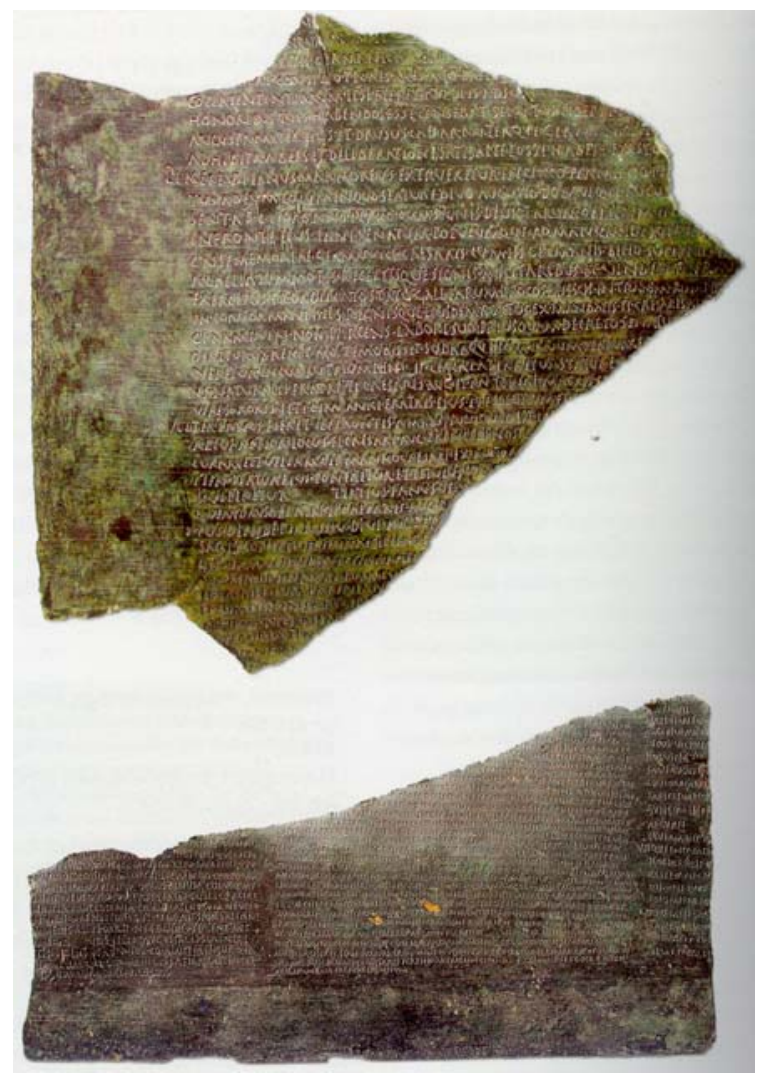

Abb. 10: Tabula Siarensis - Ausschnitte für die durch Heimtücke zugefügte Niederlage des römischen Heeres (unter Varus) und schließlich nach Regelung der Verhältnisse in den gallischen Provinzen und

\footnotetext{
${ }^{47}$ Germania magna bezeichnet zunächst einen geographischen Raum, dessen Beherrschung dann auch zu einem politischen Ziel erklärt wird. Wirtschaftliche Faktoren spielten dabei bei gewissen regional begrenzten Ausnahmen so gut wie keine Rolle. Im Hinblick auf die konkrete Politik Roms ist es wichtiger, auf die ungleichen militärischen, politischen und zivilisatorischen Voraussetzungen in diesem Raum hinzuweisen, auf die Rom entsprechend differenziert reagierte. Durchsetzen konnte Rom seinen Herrschaftswillen nur mit Hilfe der lokalen Eliten, die es durch materielle Belohnungen und andere Anreize (etwa Hebung des gesellschaftlichen Status im römischen Sozialverband durch Verleihung des römischen Bürgerrechts oder gar des Ritterranges) zu gewinnen galt. Dieses war keineswegs aussichtslos, wie schon die Verhältnisse bei den Cheruskern belegen, jedoch hätte es eines längeren Prozesses bedurft, um letztlich ähnlich erfolgreich zu sein wie in Gallien; vgl. dazu die knappe, aber informative Übersicht von CHR. GoudinEAU, Gaul, in: The Cambridge Ancient History X: The Augustan Empire, 43 BC-AD 49 (Cambridge 1996) 464-502.

${ }^{48}$ Offen bleibt bei der mehrfachen Erwähnung der Elbe als Grenze, welchen genauen Verlauf des Flusses vor allem im Hinblick auf dessen Oberlauf Rom im Auge hatte. Vgl. dazu K.-P. JoHNE, Die Römer an der Elbe. Das Stromgebiet der Elbe im geographischen Weltbild und im politischen Bewusstsein der griechisch-römischen Antike (Berlin 2006).
} 
nachdem er dann als Proconsul in die überseeischen Provinzen (des Ostens) entsandt wurde, ... im Dienst für den Staat den Tod gefunden hat. ${ }^{\text {“99 }}$ Man hat hieraus auf einen veritablen Kurswechsel in der Germanienpolitik geschlossen, indem diese Formulierung mit ihrem Hauptbezug auf Gallien sowohl den in den Siegesinschriften des Germanicus als auch im Triumphdekret formulierten Ansprüchen widerspreche und den Ambitionen des Germanicus auf eine Herrschaft bis zur Elbe einen argen Tort antue. Tatsächlich sei damit die entscheidende Wende in der römischen Germanienpolitik grundsätzlich und für alle Zeiten erkennbar festgeschrieben und jeder Anspruch auf ein Germanien aufgegeben worden. ${ }^{50}$ Jedoch bedeutet das Dekret des Senats keinen Verzicht - einen solchen zu formulieren, wäre auch offiziell weder möglich noch nötig gewesen -, es untermauert aber die ursprüngliche primäre Zielsetzung römischer Germanienpolitik, nämlich die Sicherheit Galliens vor Einfällen aus dem rechtsrheinischen Raum zu gewährleisten. ${ }^{51}$ Zum Jahr 31 n.Chr. vermerkt Tacitus: „Die hauptsächlichste Macht [Roms] aber waren die acht Legionen am Rhein, die zum Schutz sowohl gegen die Germanen als auch gegen die Gallier

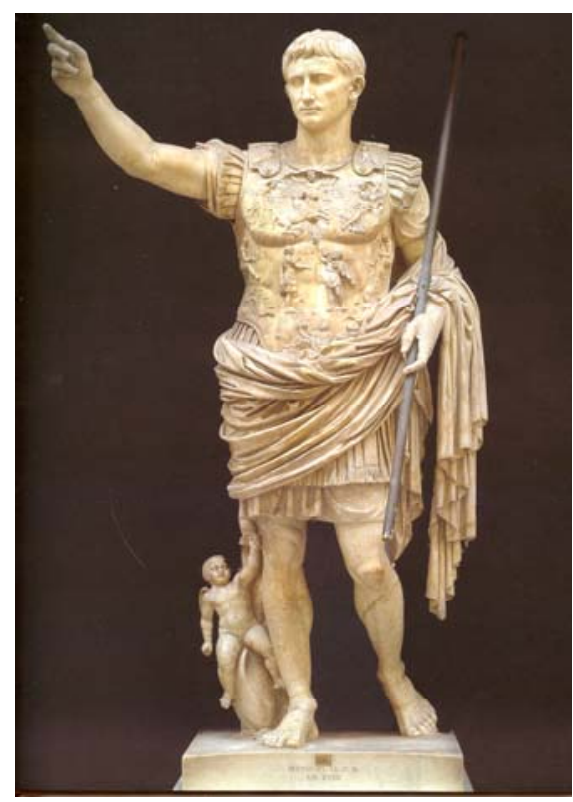

Abb. 11: Statue des Augustus von Prima Porta dienten“. ${ }^{52}$ In diese berechtigte Einschätzung sind auch die späteren Erfahrungen insbesondere des Vierkaiserjahres eingeflossen.

Hinzuweisen ist noch auf einen anderen Sachverhalt. Zum Jahresende 15 n.Chr. weihte man - so berichtet einmal mehr Tacitus ${ }^{53}$ - neben dem Saturntempel in Rom einen Triumphbogen wegen der Rückgewinnung der mit Varus verlorenen Feldzeichen unter Führung des Germanicus. Die Wiedererlangung der Feldzeichen - es waren im Übrigen bis zu diesem Zeitpunkt nur zwei der drei symbolträchtigen Adler - wird also als Zeichen des Sieges und der Unterwerfung des Gegners herausgestellt. Auch in der Laudatio auf Germanicus 19 n.Chr. wird - wie gesehen - auf die wiedergewonnenen Signa und die damit gerächte, nur durch Verrat erlittene clades Variana ausdrücklich verwiesen. Jedem Zeitgenossen in Rom war klar, dass damit politisch an die mit größtem propagandistischen Aufwand gefeierte Rückge-

\footnotetext{
${ }^{49}$ CIL VI 31199; Tab. Siar. Frg. I, Z. 13 f.

${ }^{50}$ LEHMANN, Ende (Anm. 22) passim.

${ }^{51}$ Auch Tacitus, ann. 2,83 berichtet über die Ehrenbeschlüsse und erwähnt dabei die drei Ehrenbögen „mit einer Inschrift, die von seinen Taten und seinem Tod für den Staat künden sollte“ $(2,83,2)$, ohne näher auf deren Text bzw. Texte einzugehen. Die meisten der damals beschlossenen Ehrungen hätten sich bis zu seiner Zeit gehalten, einzelne seien von vornherein nicht beachtet worden oder im Laufe der Zeit in Vergessenheit geraten (2,83,4). - Die Fundamente des Ehrenbogens am Rhein glaubt H.G. FrENZ, Der Ehrenbogen von Mainz-Kastel (Wiesbaden 1988) ebendort identifizieren zu können. H. BELLEN vermutet dagegen Kaiser Domitian als den Urheber des Baus, vgl. DERS., Der römische Ehrenbogen von Mainz-Kastel. Ianus Germanici aut Domitiani. Arch. Korrbl. 19, 1989, 77-84; dagegen wiederum H.G. FRENZ, Zur Zeitstellung des römischen Ehrenbogens von Mainz-Kastel. Arch. Korrbl. 19, 1989, 69-75. Eine eindeutige Entscheidung zugunsten der einen oder anderen Datierung erscheint beim Stand des Wissens nicht möglich. - Vgl. zu den drei Bögen und ihrer politischen und propagandistischen Bedeutung auch T. SCHMITT, Die drei Bögen für Germanicus und die römische Politik in frühtiberischer Zeit. Rev. Stor. Ant. 27,1997, 73-137.

52 Tac. ann. 4,5,1.

53 Tac. ann. 2,41,1.
} 
winnung der im Partherkrieg des Crassus 53 v.Chr. verlorenen Feldzeichen durch Augustus angeknüpft wurde, die in der Errichtung des berühmten Partherbogens 19 v.Chr. einen demonstrativen Höhepunkt erhielt. (Abb. 11-12a-d) Auch hier wurde mittels Münzprägung und anderer Medien in Schrift und Bild die Rückgabe der Feldzeichen als militärischer Sieg und Unterwerfung des Gegners ausgegeben, während die folgenden Jahre und Jahrzehnte keineswegs eine endgültige Beilegung des Konfliktes im Osten belegen. Vor der Öffentlichkeit und angesichts der Autorität und Macht des Princeps genügte also die Rückgabe bzw. Rückgewinnung der Feldzeichen, dieses als militärischen Sieg auszugeben, und die Öffentlichkeit hat diese Interpretation offenbar bereitwillig akzeptiert. Aus Sicht des Princeps musste im Falle des Germanicus also ein Balanceakt bewältigt werden zwischen Siegespropaganda und Legitimierung des gewährten Triumphes durch demonstrative Zurschaustellung des Erreichten einerseits und Aufrechterhalten des Anspruchs auf das noch nicht Erreichte andererseits. Für Tacitus war gemäß seinem Urteil in den Annalen der Lohn eines Triumphes für Germanicus zwar berechtigt, aber auf Grund der Abberufung des Germanicus gleichsam unzeitig, da dadurch die Chance zur Einlösung einer alten Verpflichtung hinfällig geworden war. Es wurde also gesiegt und triumphiert, aber letztlich nicht gewonnen, weil ein neidischer Princeps dieses verhinderte.

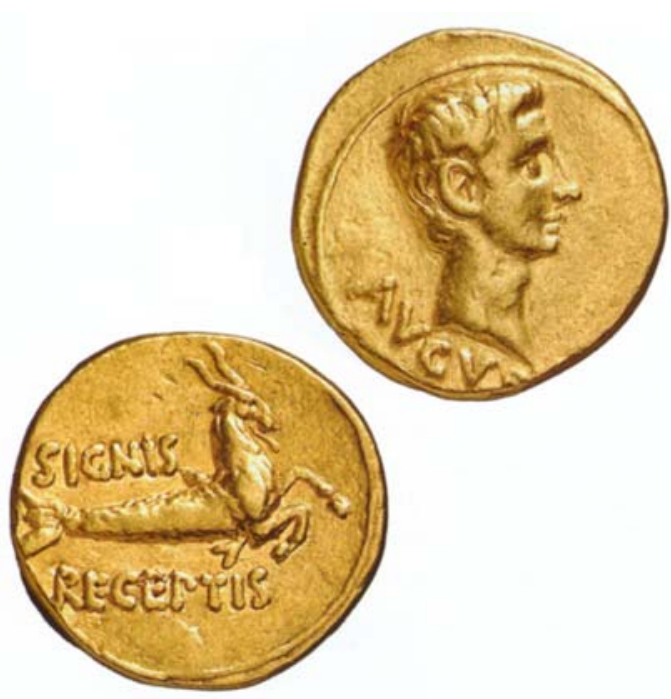

Abb. 12a: Aureus (Pergamon 19-18 v.Chr.) Rückgabe der Feldzeichen

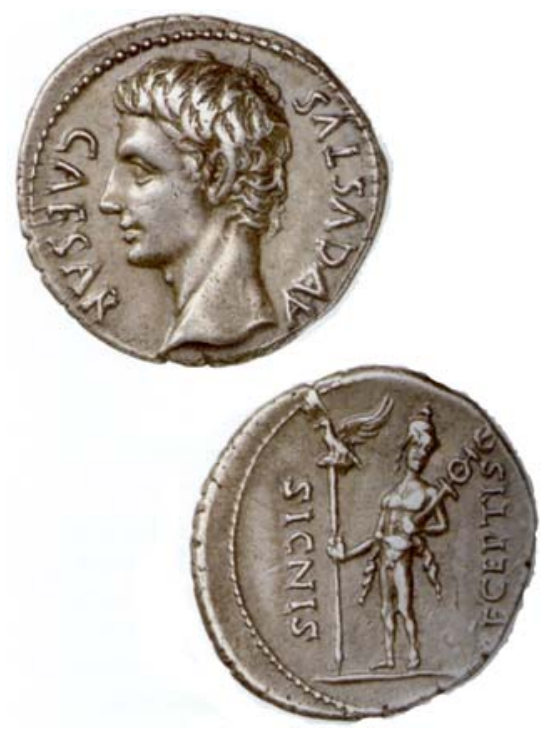

Abb. 12b: Denar (ev. Corduba ca. 19 v.Chr.) Rückgabe der Feldzeichen

Was die späteren Autoren betrifft, so beginnen sich schon bei Sueton, der wenige Jahre nach Tacitus seine Kaiserviten verfasste, die Schwerpunkte zu verschieben. Jetzt wird das Geschehen im Teutoburger Wald zugleich als ernste Staatskrise in Rom für Herrscher und Reich gewertet. Den Gegenmaßnahmen bis hin zu den Feldzügen des Germanicus und dessen Triumph wird weit weniger Gewicht beigemessen als dieses etwa bei Velleius der Fall war. Zwar unterstreicht Sueton noch einmal, dass die Feinde völlig besiegt worden seien und sich die Ziele der Germanienpolitik nicht grundsätzlich geändert hätten, doch werden die clades Variana und ihre Folgen nachdrücklicher als zuvor in ihrer Bedeutung gewichtet. ${ }^{54}$

Unmissverständlich formuliert findet sich erstmals bei L. Annaeus Florus das dezidierte und bis heute folgenreiche Urteil über die nachhaltige geschichtliche Bedeutung und Wirkung der Varusschlacht. In seinem unter Kaiser Hadrian verfertigten,

\footnotetext{
${ }^{54}$ Vgl. Suet. Aug. 23; Tib. 18-20,1; Cal. 1,1.
} 
rhetorisch aufgeputzten „Abriss der Geschichte der römischen Kriege bis auf Augustus“ vermerkt er emphatisch zu Beginn seines Berichtes über die Feldzüge der Römer in augusteischer Zeit: „Hätte er (d.h. Augustus) es doch nicht für so wichtig gehalten, auch Germanien zu besiegen! Die Schande des Verlustes war größer als der Ruhm des Gewinns.“55 Und abschließend urteilt er: „Durch diese Niederlage wurde bewirkt, dass das Imperium, welches an der Küste des Ozeans nicht Halt gemacht hatte, am Ufer des Rheins stehen blieb.“56 Im Grunde setzt sich diese Ansicht auch bei dem letzten, hier noch zu nennenden Autor fort, dem in der ersten Hälfte bereits des 3 . Jahrhunderts schreibenden Cassius Dio in seiner Römischen Geschichte. Bei ihm werden jedenfalls die Ereignisse der Jahre 10-12 ebenso in ihrer Bedeutung stark abgeschwächt wie die Feldzüge des Germanicus, über die im Gegensatz zu den ausführlichen Berichten bei Tacitus lediglich in einem einzigen Satz berichtet wird. ${ }^{57}$

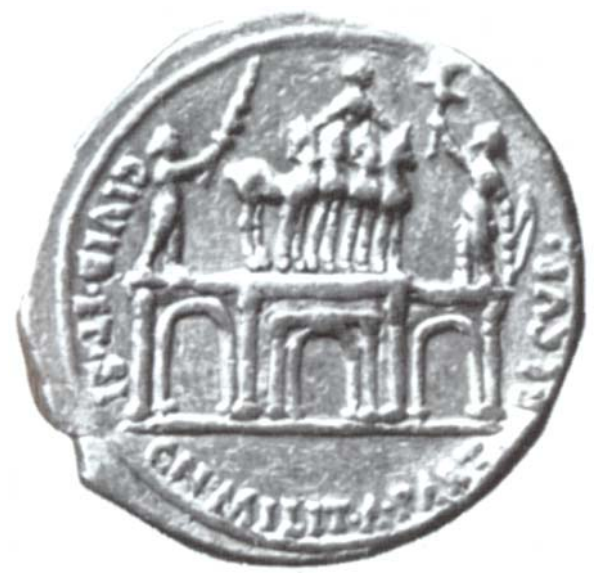

Abb. 12c: Aureus (Spanien 19-18 v.Chr.) Partherbogen

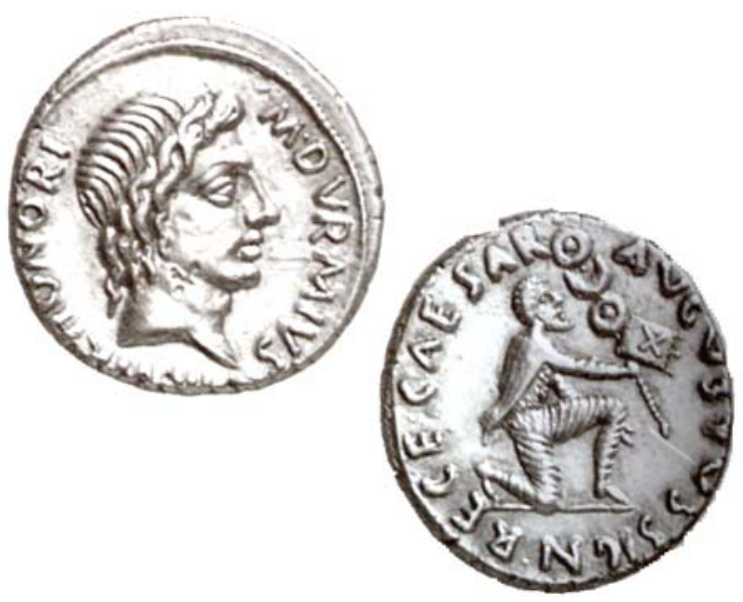

Abb. 12d: Denar (Rom 19-18 v.Chr.) Rückgabe der Feldzeichen

Zusammengefasst erweist sich, dass im Urteil der römischen Zeitgenossen der Kampf um ein Germanien bis zur Elbe von den Drususfeldzügen 12-9 v.Chr. bis zum Triumph des Germanicus 17 n.Chr. als ein kontinuierliches Geschehen angesehen wurde ohne markante Abweichungen von der durch Augustus formulierten Zielsetzung. Tacitus allerdings deckt am Beginn des 2. Jahrhunderts n.Chr. die Fragwürdigkeit jenes Triumphes auf, welcher einen endgültigen Sieg propagierte, den es eigentlich gar nicht gegeben habe, aber nicht weil er nicht möglich gewesen wäre, sondern weil er aus persönlichen Gründen zumindest aktuell versagt wurde. Erst in der Folgezeit glaubte man bei der Suche nach entscheidenden historischen Zäsuren diese mehr und mehr in der Niederlage des Varus im Teutoburger Wald 9 n.Chr. ausmachen zu können, womit etwa Florus sein Werk abschließt. Die Bedeutung des Triumphes des Germanicus und damit seiner Erfolge werden nunmehr weit geringer eingeschätzt als zuvor. Dass dieses an den mittlerweile getroffenen politischen Entscheidungen und den faktischen Realitäten liegt, wird man mit gutem Grund vermuten dürfen.

\footnotetext{
55 Flor. 2,30,21.

${ }^{56}$ Flor. 2,30,39.

${ }^{57}$ Nicht zuletzt aus diesem Grund verdanken wir Cassius Dio die ausführlichste Schilderung des Schlachtgeschehens und der Statthalterschaft des Varus, obwohl er selbstverständlich auf weit älteren Quellen basiert, vgl. Cass. Dio 56, 18-23. Zu den noch von Tacitus ausführlich geschilderten Feldzügen des Germanicus 14-16 n. Chr. findet sich bei Cassius nur der eine Satz, welcher zudem auch wieder auf die Varusniederlage Bezug nimmt: „Germanicus drang auf seinem Feldzug gegen die Kelten (= Germanen) erfolgreich bis an den Ozean vor, errang über die Barbaren einen überwältigenden Sieg, ließ die Gebeine der unter Varus Gefallenen sammeln und bestatten und erlangte auch die (verlorenen) Feldzeichen wieder“ $(57,18,1)$.
} 


\section{Germania capta - Die Lösung des Germanienfrage durch Domitian}

Im Jahr 39/40 n.Chr. unternahm Caligula offenbar einen ernsthaften Versuch, an die Tradition seines Großvaters Drusus und seines Vaters Germanicus anzuknüpfen. Nach Tacitus geriet das Vorhaben eines Germanienfeldzuges allerdings zum allgemeinen Gespött in der Öffentlichkeit, Sueton und Cassius Dio urteilen der grundsätzlich schlechten Presse des vor allem in Senatskreisen verhassten Kaisers entsprechend in gleicher Weise. ${ }^{58}$ Es scheint so, als ob der Kaiser schon bald nach Übernahme des Principats 37 n.Chr. in Nachfolge des Tiberius einen Germanenfeldzug geplant hat. Die umfangreichen militärischen Rüstungen standen allerdings in keinem Verhältnis zum Erfolg. Was letztlich den Abbruch des ganzen Unternehmens verursachte, ist nicht mehr klar erkennbar, jedoch war damit die Wiedergewinnung Germaniens nur erneut vertagt, nicht aber preisgegeben. Wiederum sollte aber durch einen Triumph der Eindruck eines entscheidenden Sieges über Germanien (und auch Britannien) erweckt werden. $^{59}$ Damals beantragte Vespasian, der spätere Kaiser, außerordentliche Spiele pro victoria Germanica, ${ }^{60}$ eine wohl in diese Zeit zu datierende Gedenkmünze für Caligulas Vater Germanicus trägt die Legende SIGNIS RECEPT(is) - DEVICTIS GERM(anis) - also: Rückgewinnung der Feldzeichen und völliger Sieg über die Germanen. ${ }^{61}$ (Abb. 13) Damit bekennt sich Caligula zu der Politik seines Vaters und der diesbezüglichen Propagierung und Fiktion ei-

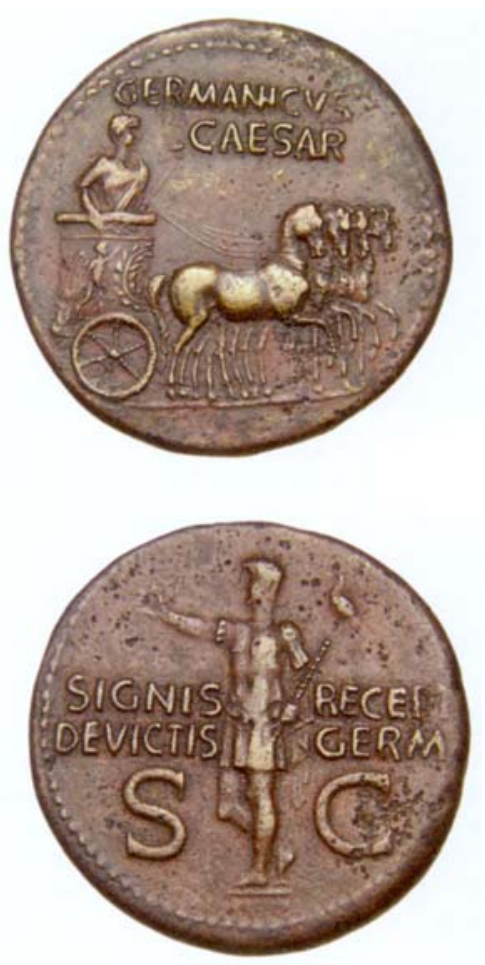

Abb. 13: Dupondius des Caligula für Germanicus nes endgültigen militärischen Erfolges über Germanien, der jetzt allerdings angesichts

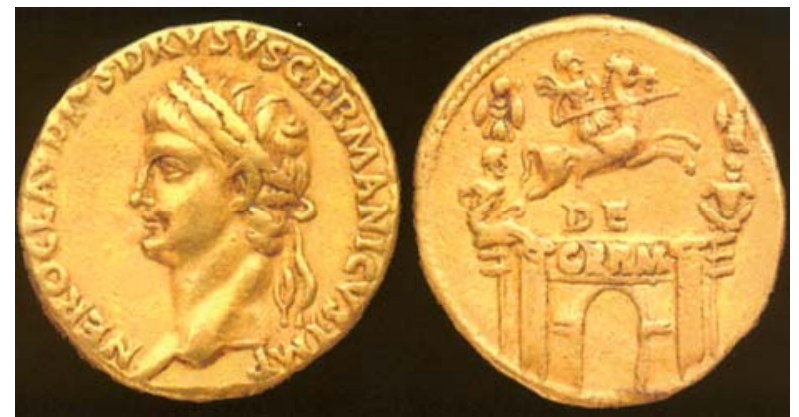

Abb. 14: Aureus des Claudius für Drusus des betriebenen Aufwandes und der erzielten Erfolge in der Öffentlichkeit und nicht zuletzt in traditionellen Senatskreisen noch stärker als Diskrepanz zwischen Anspruch und Wirklichkeit wahrgenommen werden musste als etwa 25 Jahre zuvor derjenige des Germanicus.

Die auf Caligula folgenden Kaiser hüteten sich einerseits, „diese die römische Außenpolitik belastende Hypothek konkret einzulösen, sie scheuten sich aber auch, sie zu annullieren“. ${ }^{62}$ Nach wie vor standen die acht Legionen am Rhein, und an dem Provisorium von zwei ger-

\footnotetext{
58 Tac. Germ. 37,4; Suet. Cal. 43-47; 51, 2 f. - Vgl. auch Suet. Cal. 19; ferner Cass. Dio 59,21,1-3; Aur. Vict. de Caes. 3,11.

${ }^{59}$ Suet. Cal. 46 f.; Cass. Dio 59,25,1 ff; Persius 6,43 ff.

${ }^{60}$ Suet. Vesp. 2,5.

${ }^{61}$ BMC I Cal. 160 f. Nr. 93 ff. (vgl. S. CXXXIII und CXLIV); RIC I² Gaius 112 Nr. 57. Die Zuweisung in die Regierungszeit des Caligula (37-41 n.Chr.) ist plausibler als diejenige in die ersten Regierungsjahre des Claudius mit Gedenken an seinen Bruder Germanicus. - Vgl. K. Christ, Antike Siegesprägungen. Gymnasium 64, 1957, 504 ff.

${ }^{62}$ Nesselhauf, Tacitus (Anm. 5) 236.
} 
manischen Heeresbezirken wurde gleichfalls nicht gerüttelt. Es hätte eigentlich nahegelegen, hier zwei weitere gallische Provinzen einzurichten. Auf die Vorgänge an der germanischen Front vor allem in der Zeit des Claudius und dann im Vierkaiserjahr sowie unter den ersten Flaviern kann und braucht hier nicht weiter eingegangen zu werden. Lediglich auf die Münzpropaganda unter Claudius sei besonders hingewiesen. Sie weist, was die aktuelle Politik betrifft, zwei Schwerpunkte auf: Zum einen das Jahr 41/42 und zum anderen das Jahr 47 mit der Expedition des Corbulo. ${ }^{63}$ Zeitlich etwa parallel dazu ließ Claudius in den Jahren 41-45 Gedenkmünzen an die Germanensiege seines Vaters Drusus schlagen. ${ }^{64}$ (Abb. 14) Die Thematik der Germaniensiege blieb also auch unter Claudius aktuell. Sie trat neben die Propagierung der Siege über Britannien. Die Gedenkmünzen mögen die persönlichen Bindungen zwischen Vater und Sohn bezeugen, sie sind zugleich aber auch eine politische Manifestation der Kontinuität römischer Germanienpolitik vor der Öffentlichkeit. ${ }^{65}$

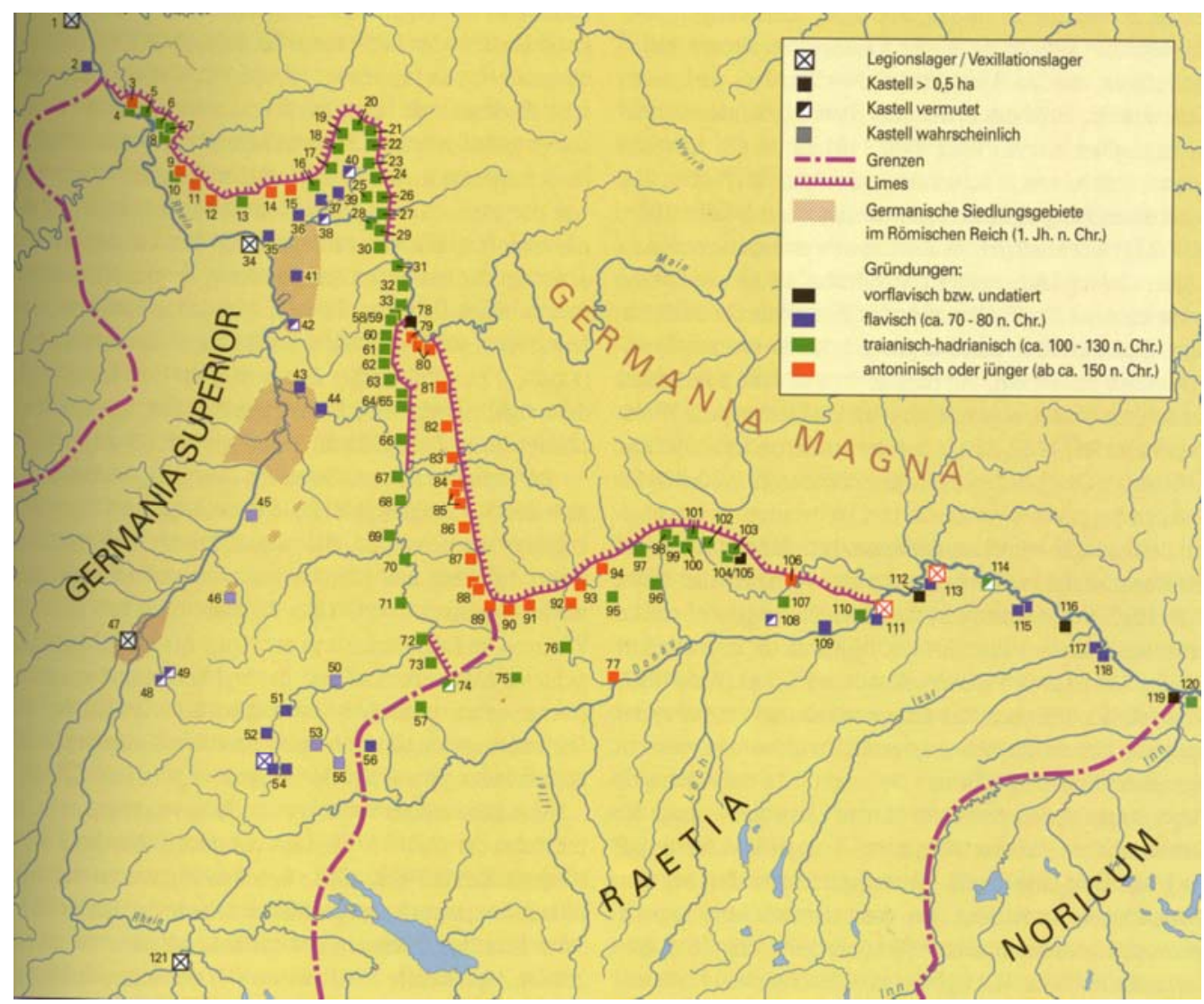

Abb. 15: Der obergermanisch-rätische Limes

Offenbar begann man sich in der Folgezeit daran zu gewöhnen, dass Rhein und Donau im Wesentlichen die Grenzen des Imperiums gegenüber Germanien bil-

\footnotetext{
${ }^{63}$ Vgl. BMC I Claud. 164 Nr. 2; RIC I ${ }^{2}$ Claud. 122 Nr. 3 (a. 41/42) und BMC I Claud. 169 Nr. 36; RIC $\mathrm{I}^{2}$ Claud. 123 Nr. 35 (a. 47): Triumphbogen mit Reiterstatue zwischen zwei Trophäen und der Beschriftung DE GERMANIS.

${ }^{64}$ Vgl. BMC I Claud. 178 f. Nr. 95-103; RIC I ${ }^{2}$ Claud. 125 Nr. 69-74: Triumphbogen mit Reiterstatue (nach rechts oder links), flankiert von zwei Trophäen, an denen je ein gebundener Gefangener hockt; dazu die Schrift DE GERM(anis), zum Teil auch ausgeschrieben.

${ }^{65}$ Die Rückberufung des Corbulo von seinen offensiven Kriegszügen im Norden der Germania magna durch Claudius spricht freilich eine andere Sprache.
} 
deten. Daran änderten auch die Ereignisse des Vierkaiserjahres und die Korrekturen vor allem in vespasianischer Zeit nichts. ${ }^{66}$

Im Jahr 81 n.Chr. trat Domitian seine Herrschaft an. Er eröffnete diese mit einem spektakulären grenzpolitischen Akt, indem er nach intensiven Vorbereitungen und mit großer Truppenmacht persönlich 83 n.Chr. zu einem Germanenkrieg aufbrach. Konkret richteten sich die Aktionen vorwiegend gegen die zwischen Lahn und unterem Main siedelnden Chatten, zur damaligen Zeit wohl der mächtigste germanische Stamm im unmittelbaren Vorfeld der Militärdistrikte, erstreckten sich aber offenbar auch auf den gesamten Bereich des nachmaligen Limesgebietes, welches nunmehr für Rom flächig erschlossen und gesichert wurde. ${ }^{67}$ (Abb. 15) Ein großer Teil

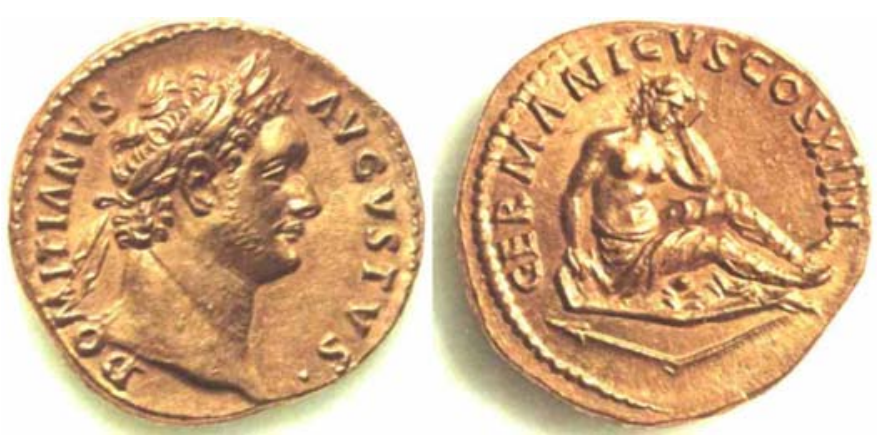

Abb. 16a: Aureus Domitians 88 n.Chr. mit trauernder Germania

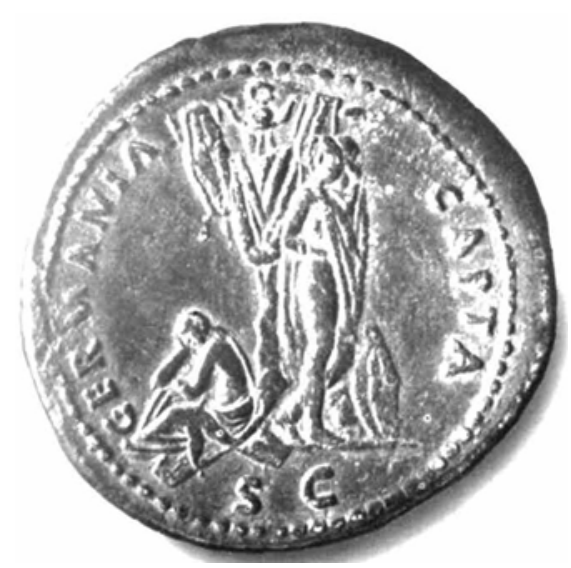

Abb. 16b: Sesterz Domitians 85 n.Chr. GERMANIA CAPTA dieser fruchtbaren Landschaften war seit Jahrhunderten dicht besiedelt, die Anwohner hatten sich zunehmend römischen Einflüssen geöffnet. Auf diese Absicherung richteten sich offenbar die konkreten Maßnahmen Domitians, weitergehende Zielsetzungen sind nicht zu erkennen. Frontinus bemerkt dazu: „Als die Germanen gewohnheitsgemäß unsere Soldaten wiederholt aus den Waldschluchten und dunklen Verstecken heraus angriffen und sich selbst den Rückzug in die tiefen Wälder freihielten, ließ Kaiser Caesar Domitianus Augustus über eine Länge von 120 Meilen Schneisen schlagen und veränderte so nicht nur die Kriegslage, sondern unterwarf auch die Feinde, deren Schlupfwinkel er bloß gelegt hatte, seiner Herrschaft." ${ }^{68}$ Damit wird auf die Anlage des sogenannten Limes angespielt. Als errungen und triumphal gefeiert wird nunmehr aber der lange erwartete und seit der Zeit des Augustus ausstehende endgültige Germaniensieg. Zwei germanische Provinzen: Germania superior und Germania inferior werden jetzt formell eingerichtet und ersetzen das Provisorium der Heeresbezirke. Sollten letztere zumindest noch die Ansprüche auf ein großes rechtsrheinisches Germanien signalisieren, so wurden jetzt - pikanterweise im Wesentlichen auf gallischem Boden $^{69}$ - diese germanischen Provinzen des römischen Volkes eingerichtet. Damit wurde das Germanienproblem als für alle Zeiten gelöst ausgegeben.

\footnotetext{
${ }^{66}$ Vgl. dazu schon weiter oben mit dem Verweis auf Sen. nat. quaest. 6,7,1; dazu Sen. nat. quaest. 1 praef. 7: Rhenus Germaniae modum faciat!

${ }^{67}$ Literarisch ist der „Chattenkrieg“ Domitians äußerst schlecht bezeugt. Bruchstücke sind bei Frontin, Strategemata überliefert; vgl. auch Stat. silv. 3,3,167 ff; Epit. de Caes. 11,2. Diese und die weiteren Quellen (Münzprägung; archäologische Funde und Befunde) sind in jüngerer Zeit umfassend von STROBEL, Chattenkrieg (Anm. 5) und BECKER, Rom (Anm. 5) ausgewertet worden.

${ }^{68}$ Frontin. strateg. 1,3,10; vgl. auch 1,1,8; 2,3,23; 2,11,7.

${ }^{69}$ Niedergermanien erstreckte sich ausschließlich westlich des Rheins, auch wenn das rechtsrheinische Vorfeld militärisch kontrolliert wurde, zu Obergermanien gehörten zwar die mittlerweile fest in Besitz genommenen Gebiete zwischen unterem Main und oberer Donau, jedoch reichte die Provinz bis tief
} 
Nie war zuvor ein römischer Sieg mit größerem Aufwand gefeiert worden. Noch 83 n.Chr. verleiht der Senat dem Imperator Domitian wohl im Zusammenhang mit dessen Triumph den prestigeträchtigen Titel Germanicus ${ }^{70}$, wenige Jahre später wird der Monat September in „Germanicus“, der Oktober in „Domitianus“ umbenannt. ${ }^{71} 85$ n.Chr. setzen die großen Münzserien ein mit der signifikantem Umschrift GERMANIA CAPTA - dem endgültig von Rom vereinnahmten Germanien - und mit Darstellung eines gefesselten Germanen sowie einer trauernd vor einem Tropaion kauernden Frauengestalt, welche die Germania symbolisiert. (Abb. 16a-d) Andere
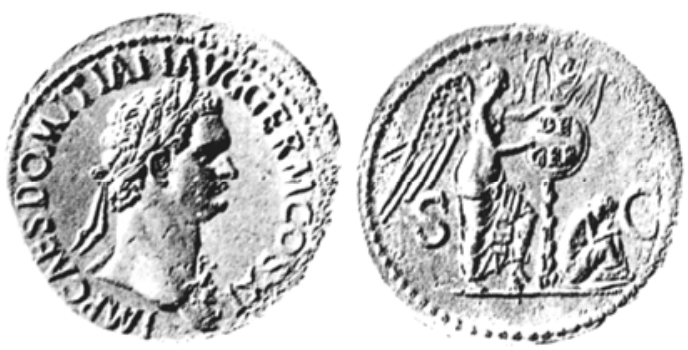

Abb. 16c: Sesterz Domitians 85 n.Chr. DE GER(manis)
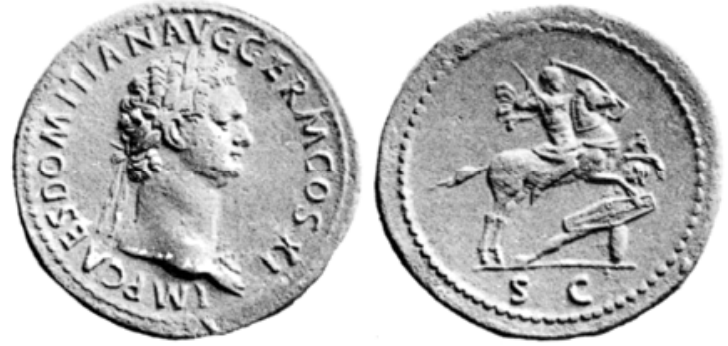

Abb. 16d: Sesterz Domitians 85 n.Chr. mit überrittenem Germanen

Emissionen zeigen Victoria, die auf den Schild DE GER(manis) schreibt, darunter wiederum die trauernde Germania, oder die klagende Germania, die auf einem Schild hockt, neben ihr ein zerbrochener Speer. Weitere Serien präsentieren den Kaiser in militärischem Gewand, vor ihm ein Germane, der kniefällig um Gnade fleht, oder den Kaiser, der mit erhobener Lanze einen vor ihm niedergesunkenen Germanen überreitet und niederstößt. Bemerkenswert auch die Personifizierung des Rheins, der zu Füßen des Kaisers liegt. Der Rhein ist jetzt als Völkerscheide erneut und wie zu Caesars Zeiten fixiert. Errichtet wurden in großer Zahl Ehrenbögen, teilweise geschmückt mit der symbolbeladenen Elephantenquadriga. ${ }^{72}$ Später mokierte sich Sueton darüber, dass der Kaiser in allen Regionen der Stadt Rom so viele Durchgänge und Triumphbögen errichten ließ, dass man sie mit dem Graffito versah: „Jetzt ist es genug“. ${ }^{73}$ Tacitus und der jüngere Plinius behaupten, aufgekaufte Germanen seien verkleidet als Gefangene im Triumphzug mitgeführt worden, ${ }^{74}$ wohl eine Unterstellung, die auch über den Triumph des Caligula berichtet wird. ${ }^{75}$ Auch in Dichtung, Skulptur und Malerei wird die Großtat Domitians reichsweit verbreitet. Statius verfasst ein Gedicht „De bello Germanico“ und besingt die monumentale Reiterstatue des über den Rhein sprengenden Kaisers. ${ }^{76}$ Martial feiert ihn als summus Rheni domitor ${ }^{77}$, als den größten

nach Gallien und umfasste nahezu ausschließlich von Kelten besiedeltes oder von keltischer Kultur und Zivilisation überformtes Land mit einer Bevölkerung, die sich seit langem römischen Einflüssen geöffnet hatte.

${ }^{70} \mathrm{Zu}$ Triumph und Titel siehe Mart. epigr. 1,4,3; 2,2,3; 6,4,2; 14,170; Frontin. strateg. 2,11,7; Tac. Germ. 37,5; Agr. 39,1; Plin. paneg. 11,4; 16,3; Suet. Dom. 13; Cass. Dio 67,4; Oros. 7,10,4 - eine bemerkenswerte Zeugnisreihe, von den Münzen und Inschriften ganz abgesehen.

${ }^{71}$ Suet. Dom. 13,3: „Nach zwei Triumphen aber nahm er den Beinamen Germanicus an und benannte die Monate September und Oktober nach seinen Namen in Germanicus und Domitianus um, weil er in dem einen seine Herrschaft angetreten hatte und in dem anderen geboren war.“ Vgl. auch Aur. Vict. de Caes. 11,2.

${ }^{72}$ Die Belege aus BMC II Dom. und RIC Dom. finden sich ausführlich gelistet und kommentiert bei WENDT, Roms Anspruch (Anm. 15) $110 \mathrm{ff}$.

${ }^{73}$ Suet. Dom. 13,2: Wortspiel mit lateinisch arcus (Bogen) und griechisch arci (genug!).

${ }^{74}$ Tac. Agr. 39,1; Plin. paneg. 16.

75 Suet. Cal. 47.

${ }^{76}$ Stat. silv. 1,1,5 ff.; vgl. 
Bezwinger des Rheins, konstatiert aber auch zu Beginn der Herrschaft Trajans, dass jetzt der Rhein nicht mehr Grenzfluss zwischen römischem und germanischem Gebiet ist, sondern dass beide Ufergebiete römisch geworden sind, womit der alte Anspruch als eingelöst ausgegeben wird. ${ }^{78}$
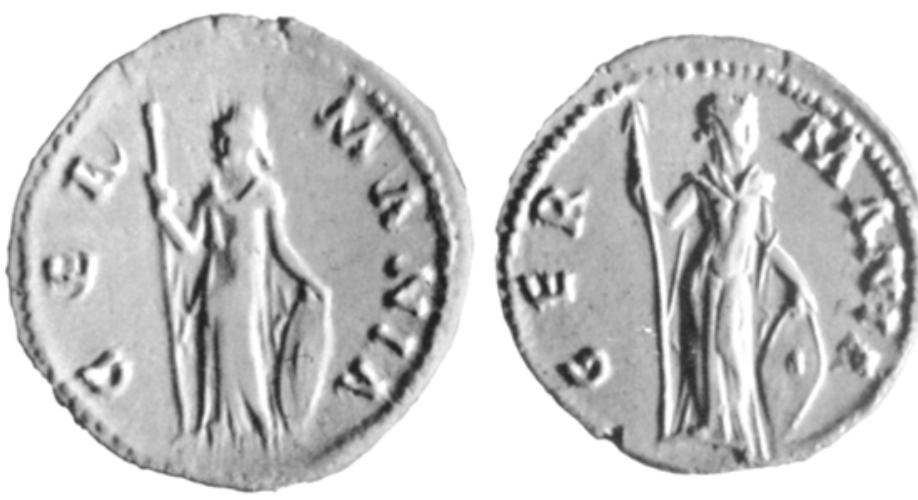

Abb. 17: Denare Hadrians mit GERMANIA in Gestalt der Minerva
Domitian hat damit eine endgültige Wende in der Germanienpolitik vollzogen, bei der fortan selbst die Fiktion einer offen gehaltenen Frage nicht mehr vertreten zu werden brauchte. Trotz Proklamation der Erfüllung einer alten Forderung nach Unterwerfung Germaniens durch entsprechende Siegesmeldungen hat der Kaiser in Wirklich-

keit letztlich auf das rechtsrheinische Germanien in den einst beanspruchten Grenzen verzichtet, was allerdings kaum mehr war als der formelle Vollzug einer sich über Jahrzehnte erstreckenden, im Kern nicht mehr umkehrbaren Entwicklung. Zum anderen hat die Tatsache, dass Trajan nicht gewillt war, an diesem Faktum etwas zu ändern, und er selber wie auch sein kurzfristig regierender Adoptivvater Nerva ganz selbstverständlich für sich den Siegestitel „Germanicus“ reklamierten, den in der Öffentlichkeit mit Ausnahme von wenigen Zeitgenossen wie etwa Tacitus kaum mehr ernsthaft als Verzicht wahrgenommenen Schlussstrich übernommen und damit unumkehrbar gemacht. Signifikantes Zeichen für die Akzeptanz der neuen Lage ist die schrittweise Verringerung der Zahl der Legionen an der Rheinfront auf nur noch vier. Das militärische Schwergewicht verlagerte sich an die Donaufront. In einer Münzserie des Kaisers Hadrian aus den Jahren 134-138 n.Chr. erscheint statt einer trauernden oder gefangenen Germania eine stehende Frauenfigur mit Schild und Speer, die einer Minerva gleicht. ${ }^{79}$ (Abb. 17) Die Umschrift bezeichnet folgerichtig die Gestalt nicht mehr als Germania subacta oder capta, sondern lediglich als Germania. Die massiv betriebene Propaganda und die realen historischen Prozesse über einen Zeitraum von mehr als 100 Jahren werden dafür
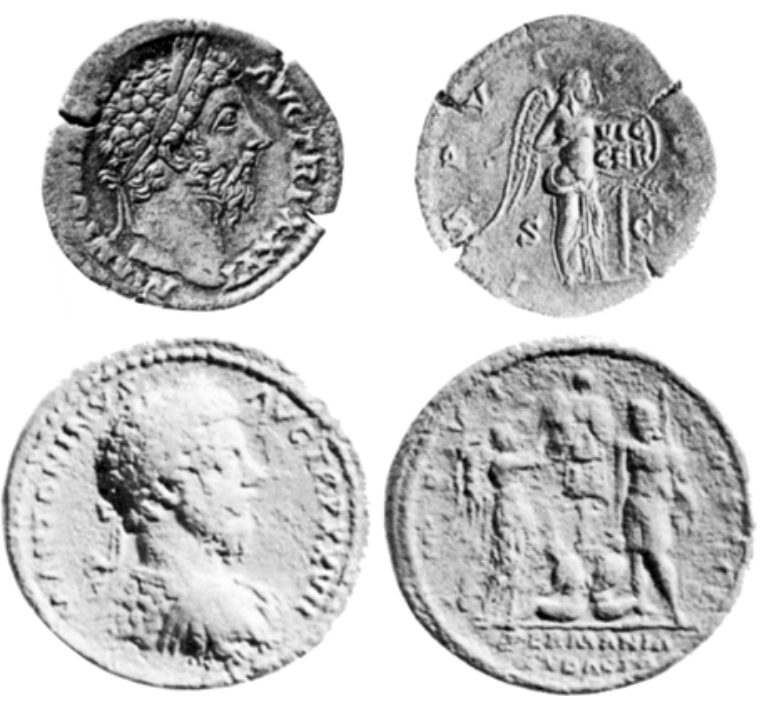

Abb. 18: Sesterz und Medaillon Marc Aurels gesorgt haben, dass man das in nüchterner Abwägung des Möglichen und auch

\footnotetext{
${ }^{77}$ Mart. epigr. 9,6,1; vgl. auch 2,2,3; 7,7,3; 9,1,3. - Siehe auch die Titulierung des Germanicus als domitor Germaniae bei Velleius Paterculus (2,129,2); dazu weiter oben mit Anm. 45. Die panegyrische Steigerung der Bezeichnung domitor zu summus domitor ist typisch nicht nur für Martial, sondern Ausdruck einer verbreiteten Praxis dieser Zeit.

${ }^{78}$ Mart. epigr. 10,7,7.

${ }^{79}$ B. OvERBECK, Rom und die Germanen. Das Zeugnis der Münzen (Stuttgart 1985) 38 f.
} 
Erforderlichen erzielte Ergebnis weithin akzeptierte und eine Kaschierung desselben jetzt nicht mehr erforderlich war, was Tacitus allerdings so nicht zu akzeptieren bereit war. $^{80}$

War Rom also trotz aller propagierten Siege über Germanien ein gescheiterter Sieger? Gemessen an einer politischen Konzeption der augusteischen Zeit, ein Germanien vom Rhein bis zum Elbegebiet dem römischen Imperium einzuverleiben, mag man von einem Scheitern sprechen. Aber dieses war keineswegs der einzige Anspruch Roms, selbst nicht in augusteischer Zeit. Imperiale Erweiterung des Reiches war kein Ziel um jeden Preis. Befriedung, Sicherheit und die Beförderung zivilisatorischer Prozesse, für die zumindest die notwendigen Rahmenbedingungen geschaffen werden sollten, waren und blieben zentrale und auch für den Bestand des riesigen Reiches notwendige Ziele. Dass diese nicht immer mit Mitteln, die den hehren Zielen entsprachen, verfolgt wurden, ist nicht zu leugnen. Nimmt man aber zum Maßstab, dass die Germanienpolitik Domitians letztlich einen Zustand stabilisierte und zum Abschluss brachte, der trotz einiger nicht zu leugnender Krisen lange Bestand haben sollte und

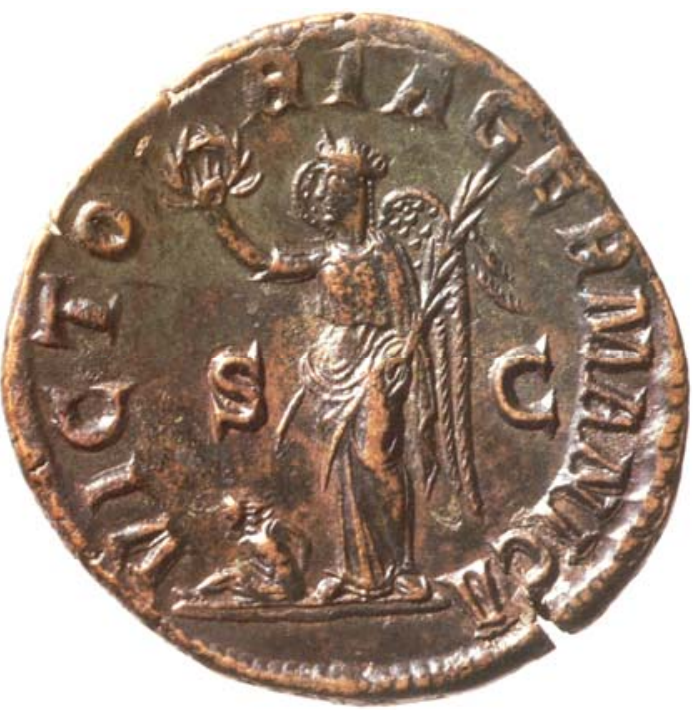

Abb. 19: Sesterz des Maximius Thrax

für weitere Jahrhunderte insbesondere Gallien aufblühen ließ, wird man kaum von einem Scheitern sprechen können.

Etwa zur gleichen Zeit, als Domitian seinen Triumph feierte, erfocht Agricola in Britannien seine Siege. Bei nüchterner Betrachtung waren die über Jahre erzielten Erfolge allerdings vergleichsweise bescheiden, die Tacitus dennoch als endgültige Besiegung Britanniens ausgab, denen nur die verdiente Anerkennung mit einen Triumph durch einen neidischen Princeps versagt wurde. In Wirklichkeit hatte Domitian durchaus den Leistungen Agricolas adäquate Anerkennung zuteilwerden lassen, wurden ihm doch die ornamenta triumphalia zuerkannt, wie in

\footnotetext{
${ }^{80}$ Es beruht vielleicht nur auf Zufall, dass sich bislang eine besiegte Germania bzw. überhaupt eine Germania-Personifikation im 1. Jahrhundert n.Chr. nur auf Monumenten und Münzen aus der Zeit des Caligula und des Domitian nachweisen lässt. Sie dürfte ebenso unter den „Bildern aller Völkerschaften“ (simulacra omnium gentium) in der Säulenhalle des Octavian, von denen Servius, Schol. Verg. Aen. 8, 722 ff. berichtet, vertreten gewesen sein wie unter den veranschaulichten unterworfenen Völkerschaften, welche vollständig im Leichenzug des Augustus präsentiert wurden (Cass. Dio 56,34,3). Eine Germania gehörte im 2. Jahrhundert n.Chr. auch zur Ausstattung des Hadrianeums, eine trauernde, gebeugte Figur erscheint dann plötzlich wieder auf Münzen aus der Zeit des Marc Aurel und des Commodus. (Abb. 18) Im Zusammenhang mit der aktuellen Diskussion um archäologische Funde vom Harzhorn aus dem zweiten Drittel des 3. Jahrhunderts n.Chr. sei auch auf Münzen des Maximinus Thrax (236/238 n.Chr.) mit der Umschrift VICTORIA GERMANICA aufmerksam gemacht, welche Programmatik auch von nachfolgenden Kaisern aufgegriffen wurde. (Abb. 19) Vgl. dazu K. SCHUMACHER / H. KlumBACH, Germanendarstellungen. Katalog des Röm.-Germ. Zentralmus. 1, Teil 1: Darstellungen aus dem Altertum (Mainz ${ }^{4} 1935$ ); OvERBECK, Rom und die Germanen (Anm. 78); E. KüNZL, Die römische Personifikation der Germania, in: Kaiser Augustus und die verlorene Republik, hrsg. vom Antikenmuseum Berlin, Staatliche Museen Preußischer Kulturbesitz (Berlin 1988) 545 f.; DERS., Germania, in: LIMC IV 1 (Zürich/Münzen 1988) 182-185. Zu den Funden und Befunden vom Harzhorn vorläufig M. Geschwinde / H. Haßmann / P. LÖnNE / M. MEYeR / G. MoOsBAuer, Roms vergessener Feldzug. Das neu entdeckte Schlachtfeld am Harzhorn in Niedersachsen, in: 2000 Jahre Varusschlacht. Konflikt (Stuttgart 2009) 228-232.
} 
vergleichbaren Fällen für erfolgreiche Generäle üblich. ${ }^{81}$ Zudem wurde er auf Veranlassung Domitians vom Senat mit einer Statue geehrt. ${ }^{82}$ In Gallien und Germanien in der gewählten räumlichen Beschränkung dagegen konnte bei gleichfalls nüchterner Betrachtung eine Grenzsicherung aufgebaut werden, welche für mehr als anderthalb Jahrhunderte zumindest im Prinzip ein friedliches Leben und eine beachtliche zivilisatorische Entwicklung zur Folge hatte, was Tacitus als Verrat an alten Zielsetzungen ansah und damit als billige Schau entlarven wollte, welche dennoch eine ungerechtfertigte Anerkennung durch den gewährten Triumph erhielt.

Das historische Urteil scheint sich so wieder zu wenden. Die schonungslose Aufdeckung einer wirkmächtigen Differenz zwischen Propaganda und Wirklichkeit durch Tacitus droht auf diesen selber und seine Schriften zurückzufallen. Nicht mehr die römische Politik und ihre propagandistische Verbreitung alleine, sondern auch das historische Urteil darüber als solches gilt es zu hinterfragen. Nicht zuletzt beruht dieses Urteil wie alle historischen Urteile auf den Maßstäben, unter denen es gefällt wird. Die Qualität eines Historikers - und zu den besten seiner Zunft ist zweifellos Tacitus zu rechnen - besteht nicht zuletzt darin, dass er es uns schwer, manchmal sogar unmöglich macht, sich seiner suggestiven Sicht und auch seinen immanent im Werk versteckten Ansichten zu entziehen. Die modernen Interpretatoren - ihrerseits selbstverständlich abhängig von den verfügbaren Quellen - sind Tacitus und seiner Deutungskunst vielfach bereitwillig, vielleicht aber gelegentlich auch allzu bereitwillig oder gar naiv gefolgt. ${ }^{83}$ Die Urteile über Arminius, die historische Zäsur in Folge der Abberufung des Germanicus und ein verbreitetes negatives Domitianbild legen hiervon beredt Zeugnis ab. Nicht selten ist jedoch die Ansicht des antiken Historikers über die historischen Vorgänge wesentlich komplexer und hintergründiger als es den Anschein hat. Eine einfache Wahrheit gibt es nicht, wir können uns nur um Annäherungen bemühen.

\section{Epilog}

Die Behauptung, dass noch im späteren 4. Jahrhundert Trier und Ausonius von den Entscheidungen in der Germanienpolitik Roms am Ende des 1. Jahrhunderts n.Chr.

\footnotetext{
${ }^{81}$ Bekanntlich triumphierte mit L.Cornelius Balbus 19 v.Chr. („ex Africa“ - acta triumph. Capitol. $\mathrm{I}^{2}$ p. 50; Strab. 3,5,3 [= 169 C]; Vell. 2,51,3; Plin. n.h. 5,36 f.) letztmalig ein römischer Feldherr, der nicht dem kaiserlichen Haus angehörte. Danach blieb der Triumph den Principes selber und den Angehörigen des Kaiserhauses vorbehalten. Der Triumph Kaiser Vespasians und seines Sohnes Titus aus Anlass des Sieges über die Juden 71 n.Chr. war dann der letzte, an dem ein Feldherr aus dem Kaiserhaus beteiligt war, der nicht zugleich Princeps war (,triumphus Iudaicus“ - Ios. bell. 7,121-158; Suet. Vesp. 8,1 (vgl. 12); Suet. Tit. 6,1; Cass. Dio 66,12,1a; Eutr. 7,20,1; vgl. Plin. n.h. praef. 3; Suet. Dom 2,1; Cass. Dio 66,7,1). Im Jahr 81 n.Chr., also 10 Jahre nach dem Triumph, errichteten Senat und Volk von Rom dem Kaiser Titus in Erinnerung an den Iudensieg einen Ehrenbogen im Circus maximus, und nach seinem Tod - also schon unter Domitian - den bekannten Bogen am Forum, wobei Letzterer formell ein Denkmal der Vergöttlichung des verstorbenen Kaisers ist, aber thematisch eng mit dem Iudentriumph verbunden ist. Den letzten echten Triumph eines Kaisers feierte Diocletian am 17.11.303 n.Chr. aus Anlass seines Sieges über die Perser. Als Ersatz für das Zugeständnis eines wirklichen Triumphes an Generäle, die nicht dem Kaiserhaus angehörten, hatte Augustus als oberster Inhaber der Befehlsgewalt (imperium) und der damit verbundenen Verfügung über die göttlichen auspicia die Verleihung von ornamenta triumphalia eingeführt, von welchem Instrument er reichlich Gebrauch machte.

${ }^{82}$ Vgl. zu den Ehrungen des Agricola Tac. Agr. 40,1; Cass. Dio 66,20,3 (wo die Urheberschaft offenbar irrtümlich Titus zugeschrieben wird); Stat. silv. 5,1,91 (ohne ausdrückliche Namensnennung).

${ }^{83}$ Vor mehr als 50 Jahren stellte K. WeLlESLEY die Frage: „Can you trust Tacitus?“. Greece and Rome n.s. 1, 1954, 13-33. Die Antwort hierauf könnte lauten: „Yes, you can, but it is difficult to understand him really“.
} 
profitierten, mag kühn, vielleicht auch tollkühn sein. Sein Liederkranz auf das reizende Germanenmädchen Bissula und seine eindrucksvolle Beschreibung des Lebens und Treibens auf der Mosel und an deren Ufern bezeugen ein friedliches Leben diesseits des Rheins. Dass aktuell die auf die Siegesgöttin getaufte „Victoria“ am Ufer der lieblichen Mosella festgemacht hat (Abb. 20), mag gleichfalls einen, wenn auch symbolischen Bogen zu unserem Thema schlagen, hat doch auch die Mosella - wie Ausonius vermerkt - bei der Kaiserstadt Trier einen Triumph des Imperators Valentinian (I.) gesehen nach Siegen über die Feinde an Neckar und oberer Donau. ${ }^{84}$ Der Erfolg wurde zwar östlich der traditionellen Rheingrenze zu Germanien errungen, aber in einem Gebiet, welches lange Zeit vor dem Zusammenbruch des Limes zum römischen Provinzgebiet gehört hatte, und jedenfalls meilenweit entfernt von der östlichen Begrenzung einer Germania, wie sie seit der Zeit des Augustus bis zu derjenigen Domitians propagiert wurde. Dennoch sei die Behauptung gewagt, dass auch Augusta Treverorum noch nach Jahrhunderten aus der Entscheidung Domitians Nutzen gezogen hat, keine weiträumige Offensive zu starten, sondern sich mit dem Bestehenden zu

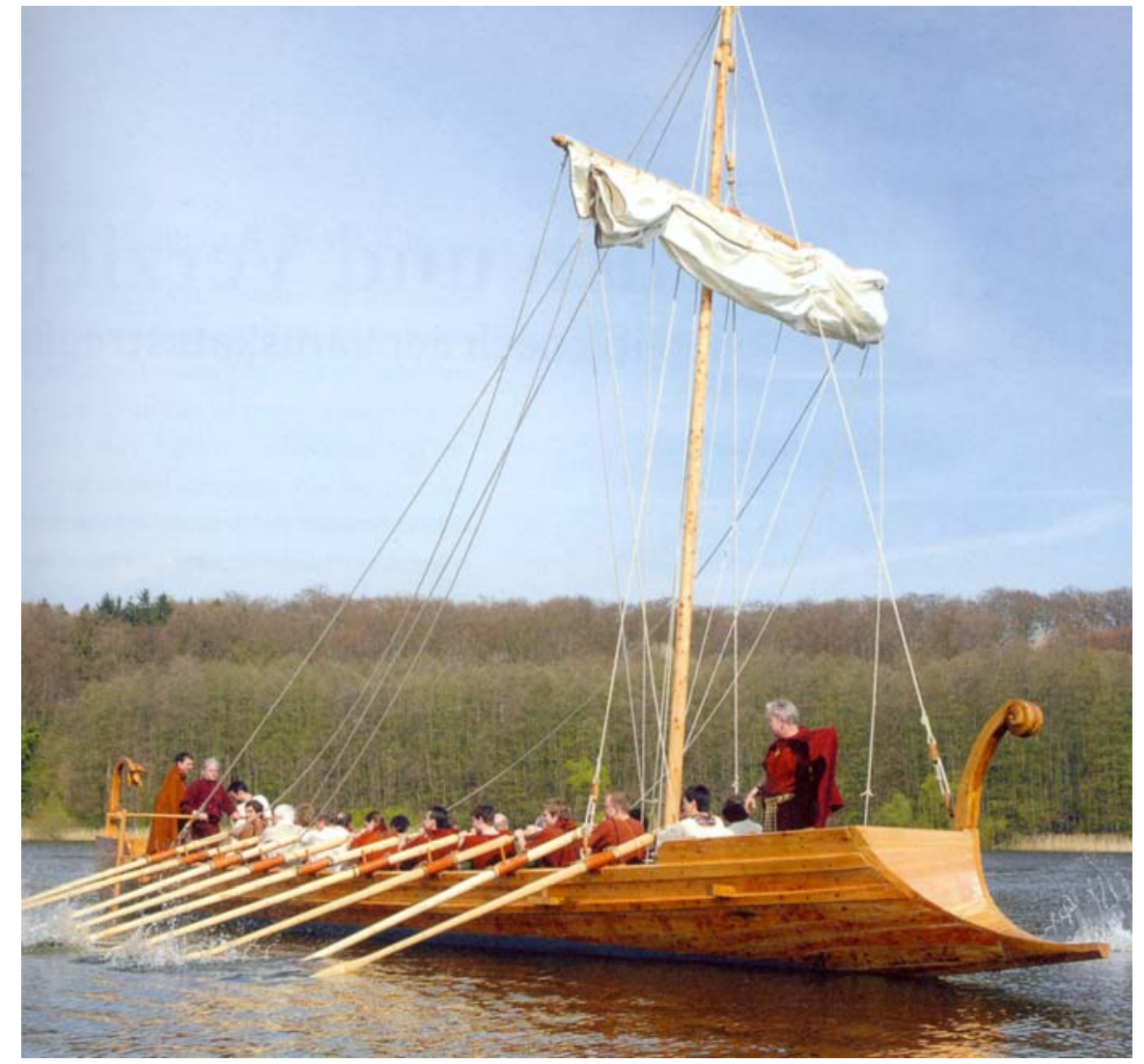

Abb. 20: Die Victoria in Fahrt

begnügen. Im Varusjahr sind wir an kühne Geschichtskonstruktionen mit großen historischen Bögen und weit reichenden kontrafaktischen Urteilen gewöhnt worden. Für allzu ernst und allzu stabil sollte man aber die Fundamente der hier aus aktuellem Anlass geschlagenen Brücke zwischen 1. und 4. Jahrhundert nicht nehmen und dieses nur als etwas bemühte, aber überzeugte Hommage an die traditionsreiche Stadt $\mathrm{Au}$ gusta Treverorum und ihre Universität verstehen.

\footnotetext{
${ }^{84}$ Auson. Mos. $418 \mathrm{ff}$.
} 


\section{Photonachweise}

Abb. 1:

Codex Leidensis Perizonianus (fol. 31). Nach: Codices Graeci et Latini photographice depicti, Suppl. 4 (Leiden 1907).

Abb. 2:

T. Bechert, Die Provinzen des römischen Reiches (Mainz 1999) vorderer Vorsatz

Abb. 3; 5; 12c; 14; 16-19:

Photodatei R. Wiegels

Abb. 4:

Grabstein des Caelius, Rhein. Landesmuseum Bonn. Photodatei CIL XIII.

Abb. 6:

R. Wiegels (Hrsg.), Die Varusschlacht - Wendepunkt der Geschichte (Stuttgart 2007) 13 (Picture - Alliance, H. Ladej)

\section{Abb. 7; 9:}

2000 Jahre Vausschlacht. Konflikt, hrsg. von der Varusschlacht im Osnabrücker Land GmbH - Museum und Park Kalkriese (Stuttgart 2009) 55, Abb. 24; 49, Abb. 17.

Abb. 8; 10; 12a,b,d; 13; 20:

2000 Jahre Varusschlacht. Imperium, hrsg. vom LWL-Römermuseum in Haltern am See (Stuttgart 2009) 318; 372; 278; 371; 209.

Abb. 11:

R. Wiegels (wie Abb. 6) 57 (Picture - Alliance, KPAIHIP / Ann Ronan Picture Library)

Abb. 15:

Römer zwischen Alpen und Nordmeer. Zivilisatorisches Erbe einer europäischen Militärmacht, Landesausstellung Rosenheim 2000, hrsg. Von L. Wamser in Zusammenarbeit mit Chr. Flügel und B. Ziegaus (Mainz 2000) 65, Abb. 49 (Michael Berger, Prähist. Staatssammlung München, Entwurf Th. Schmidts)

Abb. 18; 19:

B. Overbeck, Rom und die Germanen. Das Zeugnis der Münzen (Stuttgart1985) 40 Nr. 117 f.; 44 ff. Nr. 131 ff. 